Portland State University

PDXScholar

Civil and Environmental Engineering Faculty

Publications and Presentations

Civil and Environmental Engineering

$12-15-2015$

\title{
Multi-Criteria Evaluation of CMIP5 GCMs for Climate Change Impact Analysis
}

\author{
Ali Ahmadalipour \\ Portland State University \\ Arun Rana \\ Portland State University \\ Hamid Moradkhani \\ Portland State University, hamidm@pdx.edu \\ Ashish Sharma \\ University of New South Wales
}

Follow this and additional works at: https://pdxscholar.library.pdx.edu/cengin_fac

Part of the Civil Engineering Commons, Environmental Engineering Commons, and the Hydraulic Engineering Commons

Let us know how access to this document benefits you.

\section{Citation Details}

Ahmadalipour, Ali; Rana, Arun; Moradkhani, Hamid; and Sharma, Ashish, "Multi-Criteria Evaluation of CMIP5 GCMs for Climate Change Impact Analysis" (2015). Civil and Environmental Engineering Faculty Publications and Presentations. 321.

https://pdxscholar.library.pdx.edu/cengin_fac/321

This Post-Print is brought to you for free and open access. It has been accepted for inclusion in Civil and Environmental Engineering Faculty Publications and Presentations by an authorized administrator of PDXScholar. Please contact us if we can make this document more accessible: pdxscholar@pdx.edu. 
Ali Ahmadalipour ${ }^{1 *}$, Arun Rana ${ }^{1}$, Hamid Moradkhani ${ }^{1}$, and Ashish Sharma ${ }^{2}$

${ }^{2}$ University of New South Wales, Sydney, Australia 
12 Climate change is expected to have severe impacts on global hydrological cycle along with food13 water-energy nexus. Currently, there are many climate models used in predicting important 14 climatic variables. Though there have been advances in the field, there are still many problems to 15 be resolved related to reliability, uncertainty and computing needs, among many others. In the 16 present work, we have analyzed performance of 20 different Global Climate Models (GCMs) from 17 Climate Model Intercomparison project Phase 5 (CMIP5) dataset over the Columbia River Basin 18 (CRB) in the Pacific North-West USA. We demonstrate a statistical multi-criteria approach, using 19 univariate and multivariate techniques, for selecting suitable GCMs to be used for climate change impact analysis in the region. Univariate methods includes Mean, Standard deviation, Coefficient

21 of Variation, Relative Change (Variability), Mann-Kendall Test, and Kolmogorov-Smirnov test 22 (KS-test); whereas multivariate methods used were Principal Component Analysis (PCA), 23 Singular Value Decomposition (SVD), Canonical Correlation Analysis (CCA), and Cluster 24 Analysis. The analysis is performed on raw GCM data, i.e. before bias correction, for precipitation 25 and temperature climatic variables for all the 20 models to capture the reliability and nature of 26 particular model at regional scale. The analysis is based on spatially averaged datasets of GCMs 27 and observation for the period of 1970 to 2000. Ranking is provided to each of the GCMs based 28 on the performance evaluated against gridded observational data on various temporal scales (daily, 29 monthly, and seasonal). Results have provided insight into each of the methods and various 30 statistical properties addressed by them employed in ranking GCMs. Further; evaluation was also 31 performed for raw GCM simulations against different set of gridded observational dataset in the 32 area.

35 Keywords: Statistical Multi-Criteria Analysis, Climate Change, Pacific North-West (PNW), 36 Columbia River Basin, Global Climate Model (GCM) 
38 Climate change is affecting environmental systems at global and regional scales (Moradkhani et

39 al. 2010; Woldemeskel et al. 2012; Wang et al. 2013; Önol et al. 2014). Over the past decades,

40 several institutions have provided future climate datasets for the Intergovernmental Panel on

41 Climate Change (IPCC) (Pierce et al. 2009; Rupp et al. 2013), which in turn have been widely

42 used to study climate change impacts. The World Climate Research Programme's Coupled Model

43 Inter-comparison Project Phase 5 (CMIP5) is the latest dataset available. There have been

44 significant improvements from the former counterparts, in knowledge and understanding of the

45 climate using these new generation climate models. Despite these improvements, there are still

46 large uncertainties associated with the climatic scenarios. Reliability of GCMs to simulate

47 observed climate and consequently climatic scenarios at a regional scale is still of major concern

48 (Rupp et al. 2013).

49 Evaluation of uncertainties associated with GCMs is an important aspect to consider when

50 assessing future scenarios, e.g. their capability to simulate reliable fine scale datasets. It has been

51 widely discussed and accepted that model uncertainty plays a big role in future projections of

52 climatic data (Hawkins and Sutton 2011; Najafi et al. 2011). The estimation of model efficiencies

53 is based on their performance under current or past climate conditions, and to some extent requires

54 extrapolation to future conditions; although there are reported issues with the assumption of

55 stationarity (Buser et al. 2009; Christensen et al. 2010). The large number of datasets, offered by

56 various scenarios/forcings and models, adds to the uncertainty to be dealt with, along with the huge

57 computational needs, among other varied concerns. It also adds to the ongoing debate about the

58 reliability of GCMs to resolve features at local scale, which often are downscaled using statistical

59 or dynamical downscaling techniques (Fowler et al. 2007; Samadi et al. 2013). Understanding of 
60 the model processes would provide more reliable results and thus reliable future predictions. Since

61 GCMs produce results on global scale (coarser resolution, table 1), they tend to over/under-

62 estimate climatic variables on regional and global scales, failing to resolve the micro-scale climate.

63 Furthermore, due to natural variability in GCM predictions, uncertainty is inevitable in their

64 predictions. The natural variability of GCMs is higher in finer temporal scales, and thus predictions

65 at various timescales reveal different uncertainties (Hawkins and Sutton, 2011). Therefore, it is

66 necessary to study GCMs at different regions and assess their performance in

67 predicting/replicating the observed climate of the region, which would further reduce the

68 computational needs and decrease the uncertainty associated with climate prediction. Each model

69 accounts for large amounts of climatological information leading to huge data size which in turn

70 requires vast computations. Thus, selecting models that aptly represents the regional scale climate

71 is a necessary first step before a regional climate change impact assessment can be performed.

72 Researches have been conducted in the past decade with the intention of providing ranking to

73 GCMs performance with varied intents. Both qualitative and quantitative methods have been

74 suggested in literature (Maxino et al. 2008; Pincus et al. 2008; Chiew et al. 2009; Christensen et

75 al. 2010; Johnson et al. 2011) Miao et al. (2012) used four metrics, along with fitting Probability

76 density functions (PDFs), to analyze the performance of CMIP3 precipitation and temperature

77 datasets for China in historical period of 1960 to 1999. Rana et al. (2013) analyzed a five model

78 ensemble of daily observed precipitation series over the period of 1961 to 2009 for Gothenburg,

79 and assessed each model's performance. They used statistical analysis for daily and multi-day

80 extremes, among others. Wójcik (2014) evaluated variability of GCMs in 45 CMIP5 GCMs over

81 Europe and North Atlantic. Basic statistical methods of MAE (Mean Absolute Error), correlation

82 coefficient, and standard deviation were used to assess the reliability of GCMs in reproducing 
83 atmospheric circulation patterns in historical period of 1971-2000. Raju and Nagesh Kumar (2014)

84 ranked 11 GCMs over India for the climate variable 'precipitation rate' using 5 performance

85 indicators (correlation coefficient, normalized root mean square error, absolute normalized mean

86 bias error, average absolute relative error and skill score). Researchers have also focused on

87 regional performance analysis of GCMs in the Pacific Northwest USA. Werner (2011) evaluated

8822 GCMs from CMIP3 datasets using various performance metrics generated by work from other

89 groups namely Pincus et al. 2008; Pierce et al. 2009; Jost et al. 2012. Both global as well as regional

90 performance analysis was used to have robust results. They used results of those studies and

91 determined several decision factors. Some factors were based on statistical measures obtained from

92 GCMs, and some considered availability and performance of GCMs in other studies. Recently,

93 Rupp et al. (2013) used 41 CMIP5 GCMs and 24 CMIP3 GCMs and evaluated each model's

94 simulation for the Pacific Northwest USA with observational gridded dataset. They defined 19

95 performance metrics and evaluated each model according to their performance on those metrics.

96 In the present study, we have analyzed the performance of 20 GCMs from CMIP5 dataset based

97 on their performance in accordance with historical gridded observational data (Livneh et al. 2013)

98 over Columbia River Basin in Northwest USA. We have based our analysis on precipitation and

99 temperature, since precipitation is the main input for hydrological models, and temperature plays

100 a key role in the estimation of evaporation and evapotranspiration (Woldemeskel et al. 2012). A

101 wide range of statistical methods have been applied on the raw simulations from GCMs and

102 gridded observational data to assess their performance based on the properties/attributes captured

103 by the particular statistical method in the historical period of 1970-2000. Nevertheless, our

104 evaluation method is general (based on different statistical properties of data i.e. univariate and

105 multivariate analysis) and can be used in any other regions to evaluate climate models. The 
motivation for this study included analysis of daily data, which is reported in results section, but

107 we have also performed the analysis on monthly and seasonal (summer and winter) dataset. For

108 brevity, only daily dataset statistics are reported in results section and same could further be used

109 in hydrological analysis on daily time scale. Other temporal scales are reported only for the final

110 evaluation matrix. Effect of change of observational dataset was also studied by evaluating the raw

111 GCM simulations with Abatzoglou (2013) gridded observational dataset in the study area.

112 Results of this study were utilized in parallel efforts to assess the impacts of climate change and 113 global warming on characteristics of climatic variables over Columbia River Basin (CRB). Rana

114 and Moradkhani (2015) analyzed spatial, temporal, and frequency changes of future precipitation

115 and temperature in CRB using this set of selected GCMs. The application of 40 different

116 downscaled models/scenarios for various timescales has provided insight into probable changes in

117 future climate. Demirel and Moradkhani (in press) applied Bayesian Model Averaging to reduce

118 the uncertainty in GCM predictions for studying the seasonality and timing of historical

119 precipitation over Columbia River Basin. Their results identified the changes in seasonality and 120 persistence of extreme precipitation events for the study region.

121 The paper is divided into 6 sections, introduction followed by description of study area and data.

122 This is followed by description of univariate and multivariate statistical procedures used for 123 analysis and results, discussion and finally summary and conclusion is outlined in section 5 and 6.

\section{Study Area and Data Used}

125 Daily records of precipitation $(\mathrm{P})$ and near surface temperature $(\mathrm{T})$ in the study region (Figure 1) were collected for 20 GCMs (table 1) of the CMIP5 historical experiment (Taylor et al. 2012). The

127 areal daily average for precipitation and temperature is calculated over the Columbia River Basin 
128 (Figure 1) for each GCM along with other accumulated temporal scales of monthly and seasonal

129 (summer and winter) datasets (accumulation from daily values). The GCM data is evaluated

130 against gridded daily dataset acquired from University of Washington (Livneh et al. 2013)

131 (hereafter referred to as gridded observational data), which has a spatial resolution of 1/16 Deg.,

132 and is available for the historical period of 1970-2000. This is the most widely used (and reliable)

133 dataset in study area. Gridded observational dataset (Abatzoglou 2013) from University of Idaho

134 with spatial resolution of $1 / 24$ Deg. was also used to study the effect of observational dataset on

135 selection/evaluation of GCMs. GCMs and gridded observation data each have different spatial

136 resolution and hence, they cannot be compared on grid scale without statistical manipulations, like

137 interpolation. Therefore, spatial average values of GCMs and observation are used in all the

138 analysis. Also, each method is applied separately on Precipitation and Temperature.

\section{Methods}

140 The performance evaluation matrix deployed in this paper is based on the ability of particular

141 GCM to reproduce the statistical properties/attributes of the gridded observational data, and no

142 direct comparison of time series is done for simulations and observations. We have not based the

143 evaluation of models on a particular matrix/method as opposed to what is suggested by others

144 (Hawkins and Sutton 2011; Deser et al. 2012a; Deser et al. 2012b; Deser et al. 2014). Instead we

145 have reported the evaluation on a number of metrics to provide a broader basis for assessment and

146 decision making on various time scales based on user interest. This would also help to remove

147 subjectivity connected with regional/local properties or previous knowledge of the area concerned.

148 Although, choice of relevant climate variables/spatial/temporal resolutions and ranges etc. would

149 still be subjected to user discretion and not target study area. Thus, the process is objective and

150 based only on the statistical properties of GCM data and that of gridded observational data and the 
151 user need not have any prior knowledge of the area in concern, which in turn adds to the advantage

152 of its application in any area. The performance of different GCMs in a particular method can also

153 be investigated. Furthermore, it is possible to compare the ability of different methods as they

154 address various statistical properties.

155 Various performance metrics have been proposed by researchers. Some of these metrics focus on 156 the mean climatological state, whereas others are related to temporal variability (e.g. seasonal

157 variations, yearly and decadal changes). Since there is no standard methodology to evaluate

158 climate models, we chose metrics, which are statistically credible, and are able to examine the

159 statistical characteristics of models in accordance with gridded observational data. The metrics

160 compare the distribution properties of models (mean, variance, correlation, among others) as well

161 as the trends and relative changes. Various metrics applied focus on certain statistical properties

162 of the dataset itself. An overall of 10 metrics are employed to compare the performance of each

163 model (and each temporal scale) with the gridded observational data; this is the basis of multi-

164 criteria analysis. Thus, the end user has 40 metrics ( 4 temporal scales*10 evaluation methods) for

165 each of the climatic variable, i.e. precipitation and temperature; total of 20 metrics for ranking

166 GCMs on particular temporal scale. The metrics can be classified under univariate and multivariate

167 statistical measures of performance.

168 Univariate analysis explores each variable in a data set, separately. It looks at the range of values,

169 as well as the central tendency of the values. It describes the pattern of response to the variable.

170 The metrics that are used for univariate statistical analysis in the study are:

171 1. Mean

172 2. Standard deviation 
4. Relative Change (Variability)

175 5. Mann-Kendall Trend

6. Kolmogorov-Smirnov test (KS-test)

177 Multivariate statistics is the form of statistics encompassing the simultaneous observation and 178 analysis of more than one outcome variable in the dataset. The following multivariate techniques 179 were applied in the study:

7. Principal Component Analysis (PCA) or Empirical Orthogonal Function (EOF)

8. Singular Value Decomposition (SVD) or Maximum Covariance Analysis

184 All the metrics are applied on spatially averaged GCMs and observational datasets. For

185 multivariate metrics, the analysis is performed after standardizing datasets. A brief explanation of 186 methods along with the statistical properties they address is provided in the following paragraphs.

187 The methods are applied for both precipitation and temperature separately. More detailed 188 information about multivariate methods can be found in Bretherton et al. (1992).

\section{$189 \quad 3.1 \quad$ Univariate Statistics}

190 Mean of dataset refers to the central tendency either of a probability distribution or of the random 191 variable characterized by that distribution; and Standard deviation measures the amount of 192 variation or dispersion of data from average/mean. Calculating them will reveal how data is 193 distributed, and the range that most of the average values occur. The coefficient of variation is 194 defined as the ratio of the standard deviation $\sigma$ to the mean $\mu$, i.e. normalized measure of dispersion 
195 of a probability/frequency distribution. It removes the dependency of standard deviation on the

196 mean, and investigates the variability in relation to mean of population. In this study, coefficient

197 of variation is calculated for all temporal scales of each GCM and also for gridded observational

198 data. For temperature, CV is calculated using data in Kelvin.

199 Relative change (RC), in quantitative science, evaluates the relative difference or variability of 200 models while taking into account sizes of things being compared. Since there is large variations in

201 daily values of precipitation and temperature, relative change is only calculated at the yearly scale.

202 Thus for each GCM, absolute annual RC is calculated in the study period for both variables. Then,

203 average absolute RC over the entire period is used for ranking, and the GCM which has a similar

204 average absolute RC to observation receives a higher score. Relative change of temperature is

205 calculated using data in Kelvin. Large changes infer little or no consistency in

206 precipitation/temperature between different years. Relative change removes the dependency of

207 standard deviation on mean (Rana et al., 2013).

208 Trends- Mann-Kendall Test: The rank-based Mann-Kendall test is a non-parametric test i.e.

209 independent of the statistical distribution of the data. The Mann-Kendall trend test is based on the

210 correlation between the ranks of a time series and their time order. For more information, readers

211 are referred to Belle and Hughes (1984) and Govindarajulu (1992). Ranking is performed using

212 the test statistics (z-value) at the given significance level (95\% in this case). Using test statistics,

213 one can easily understand if the trend is positive or negative. Furthermore, since all datasets have

214 the same length and the confidence interval is constant, significant test statistics value can be easily

215 found. The results are analyzed as follows: 
216 (a) If the test statistics obtained for gridded observational data is positive, models with positive

217 and closer statistics to observation will receive a score of 5. Values calculated for other models are

218 divided into 4 groups based on their test statistics, and ranking is performed based on the proximity

219 to observational statistics.

220 (b) If the test statistics obtained for gridded observational data is negative, models with negative

221 and closer statistics to observation will receive a score of 5. Values calculated for other models are

222 divided into 4 groups based on their test statistics, and ranking is performed based on the proximity

223 to observational statistics.

224 Kolmogorov-Smirnov test (KS-test) is one of the most useful and general non-parametric methods

225 for comparing two samples to decide whether the samples come from a population with a specific

226 distribution. The null distribution of this statistic is calculated under the null hypothesis that the

227 samples are drawn from the same distribution (in the two-sample case) or that the sample is drawn

228 from the reference distribution (in the one-sample case). It is sensitive to differences in both

229 location and shape of the empirical cumulative distribution functions of the two samples. KS-test

230 is distribution free test and is based on looking at the maximum vertical distance between the

231 ECDF of the two distributions. More information about KS test can be found at Huth and Pokorn

232 (2004). In this study, the two-sample KS test is applied over samples of each GCM and

233 observation, and for each case test statistics are calculated and used for ranking. This is done for

234 all temporal scales on daily, monthly, and seasonal.

\section{$235 \quad 3.2 \quad$ Multivariate Statistics}

236 Principal Component Analysis (PCA) or Empirical Orthogonal Function (EOF): It simplifies

237 (using orthogonal transformation) the complex interrelationships in a dataset by constructing one 
or few variables, which enable easier assessment of the relationships (Moradkhani and Meier 2010;

239 Rana et al. 2012). PCA maximizes the variance explained by weighted sum of elements in two or

240 more fields by recognizing linear transformations of the dataset that describes the variance as much

241 as possible in a few number of variables. PCA specifies the relationship among various modes of

242 variability by separating the modes in time series of different fields. It searches for basis vectors

243 that can describe the behavior of multiple variable metrics (Nishii et al. 2012). PCA isolates the

244 modes of variability observed in time series of different fields and gives their relationships in

245 separate modes. In this study, PCA is performed on standardized data of each GCM and the gridded

246 observational data for all temporal scales. Desired components are selected, and eigenvalues of

247 each model are compared to the eigenvalue of gridded observational data.

248 Singular Value Decomposition (SVD) or Maximum Covariance Analysis: SVD, a matrix

249 operation, is applied to asymmetric or not squared matrices in the diagonalization of PCA. It

250 provides the spatial patterns from the two fields that explains most of the covariance between them

251 and thus also called Maximum covariance analysis. Maximizing the covariance between linearly

252 related variables makes SVD neutralize the linear combination of variables, which seem to be

253 linearly related to each other. The principal difference in both the techniques applied here is

254 maximization of variance in PCA whereas we maximize covariance of predictor and predictand in

255 case of SVD. For more information and detailed explanation of SVD refer to Bretherton et al.

256 (1992). Covariance explained by predictor in the predictand field in a particular mode is used to

257 compare the relative significance of certain mode in the expansion. The correlation coefficient

258 between the predictor and predictand provides information about how strong the two fields are

259 related to each other (Wallace et al. 1992). In this study, SVD is applied to the cross-covariance

260 matrix of the standardized GCMs and observation, where gridded observational data is assumed 
261 as the predictand, and the models are treated as predictors. Heterogeneous correlation map-

262 defined as the correlation between model values and the first expansion coefficient, obtained from

263 each model is taken into account, and the model with higher correlation gets a higher score,

264 performed for each temporal steps. It should be noted that there is no direct comparison of the time

265 series itself, but instead with attributes of the time series, expansion series, and weight vectors, on

266 various temporal scales i.e. daily, monthly, and seasonal.

267 Canonical Correlation Analysis (CCA): CCA measures the linear relationship between two multi-

268 dimensional variables i.e. of the cross-covariance matrices of the data. It finds two optimal bases

269 (one for each variable) according to correlation, and finds the corresponding correlations. CCA

270 tries to find the bases in which correlation matrix between the variables is diagonal and the

271 correlations on the diagonal are maximized. It might be treated as a special form of empirical

272 orthogonal function (EOF) analysis, where it can describe the correlation between predictor and

273 predictand more comprehensively using various modes in it (Barnston and Ropelewski 1992).

274 CCA is applied on standardized data in the present study. Since CCA is a linear technique, its

275 applicability is narrowed to relations wherein predictand and predictor have the same response.

276 Therefore, it brings information about small perturbations than to assess strong nonlinear relations

277 (Wójcik 2014).

278 More information and detailed explanation of CCA can be found in Wilks (2011). The differences

279 among PCA, SVD, and CCA can be found at Bretherton et al. (1992). Spatial canonical

280 correlations obtained from CCA performed on each GCM and gridded observational data is used

281 to rank them accordingly for each of the temporal scales in consideration. More details about

282 ranking and criteria used can be found in section 3.3. 
283 Cluster Analysis: It methodologically tries to separate objects in various groups each having more

284 similarities together than with other clusters (Bratchell 1989). Cluster analysis is an appropriate

285 method to classify climate zones, and is becoming more practical in atmospheric research studies

286 (Unal et al. 2003). It graphically depicts the relation among various observations by producing

287 dendograms. Dendograms (also called cluster trees) present a number of levels of (dis)similarities,

288 and place observations in different levels according to their similarities. Here we have constructed

289 clusters from the agglomerative (start with points as individual clusters and, at each step, merge

290 the closest pair of clusters) hierarchical clustering as generated by the linkage function. We have

291 used flexible linkage method to classify models since it seemed to work more reasonable with

292 climatic and hydrological datasets, based on literature review. Each GCM has a linkage distance

293 to connect to the gridded observational data. These distances are extracted for models and they are

294 ranked accordingly for all temporal scales. More information about cluster analysis can be found 295 in Wilks (2011).

296 A summary of the type/characteristic of datasets used to perform each method is provided in table 2972.

\section{$298 \quad 3.3 \quad$ Model ranking}

299 Evaluating GCMs with various statistical tests helps investigate the advantages and caveats of each

300 model/GCM from various statistical aspects in respect to gridded observational dataset. However,

301 it brings some challenges to interpret the results. In some studies, researchers have eliminated those

302 metrics, and provided their ranking with some of their previously chosen metrics (Werner, 2011).

303 Whereas in some researches, weights have been assigned to each method and then final ranking is

304 presented based on weighted methods (Rupp et al., 2013), with some working on previous 
305 knowledge of the area to eliminate the method/model which in turn brings subjectivity in the 306 scenario.

307 In this study, we have chosen metrics which evaluate the important aspects of climate data and are 308 not significantly redundant. Although some of the methods might seem similar and evaluate same 309 feature, they are targeting different aspects of datasets. Moreover, in each method, outlier GCMs 310 are excluded with lowest rank assigned, and thus ranks obtained by each method is checked to 311 avoid possible overrating of a model. In other words, considering one method, if one of the GCMs 312 performs poorly, it is first excluded to provide a more meaningful comparison among the GCMs.

313 This can be verified in the figures of final rankings in results section. Metrics are treated equally 314 to treat the methods objectively, since adding weights will be based on another assumption, which 315 may increase the uncertainty. We have provided results of each metric for all models for further 316 use in certain applications and for all the temporal scale in consideration. Use of various temporal 317 scales, i.e. daily, monthly, and seasonal provides a wide range of array for stakeholders and 318 decision makers to make decision based on the utility. It also contributes to study of various low 319 frequency events that are not prominent on daily scale but are part of monthly and seasonal scale 320 data, thus accommodating all the possible ranges of variability explained by the data. Daily scale 321 results are emphasized throughout the study due to importance of daily data in driving hydrological 322 models and analysis. Rankings are based on assigning scores of 1 to 5 for each metric. In other 323 words, performance of each model will be compared to the gridded observational data and 324 consequently it will receive a score of 1 to 5 on each metric, where 1 shows the least efficiency 325 and 5 represents the best performance on the metric. Overall ranking is the summation of scores 326 obtained for precipitation and temperature in each method for a GCM. Average of overall ranks of 
each GCM is calculated and will be used to select GCMs on each time scale. Representative results

328 are explained in the result section for each of the methodology applied.

Results

330 Evaluating each metric and studying the performance of models in them is an important aspect of 331 investigating the overall performance for both variables. Therefore, results for each metric will be

332 evaluated and discussed in the following sections and eventually ranking would be done based on

333 results of each metric. An overall ranking based on averaged score for both variables would be

334 provided thereafter.

\section{$335 \quad$ 4.1 Raw GCM Simulations and Gridded Observational Data}

336 Before evaluation of GCM simulations, it is vital to explain the data itself and its characteristics.

337 Boxplots and violin plots are the tools used to investigate/illustrate the raw GCM simulations and

338 gridded observational data. Figure 2 illustrates boxplots of precipitation and temperature. In the

339 figure, plots A, B, and C are depicting GCM raw simulation for each model and the gridded

340 observational data for daily and seasonal precipitation; plots $\mathrm{D}, \mathrm{E}$, and $\mathrm{F}$ are representing

341 temperature for the same timescales. In the figure, outliers are specified using markers with red

342 color along with median in center of box and $25^{\text {th }}$ and $75^{\text {th }}$ percentiles marking box boundaries.

343 Since there are many days with no precipitation, the median is around zero, and therefore, most of

344 the data is assumed as outliers. However, for temperature (Fig. 2c), median and quartiles are clearly

345 obvious and models can easily be compared to the gridded observational data. From figure 2, for

346 daily precipitation (plot A), it can be noted that most of the models are overestimating the

347 precipitation values and underestimating the dry days, all the models have median, along with $25^{\text {th }}$

348 and $75^{\text {th }}$ percentiles, higher than the gridded observational dataset. Overestimating precipitation is 
more noticeable in warm season (plot B) when all GCMs are predicting higher values, and only

350 CanESM2 shows low bias. Precipitation prediction of GCMs has less bias in cold seasons (plot

351 C). On the other hand, for daily temperature, median and quartiles seem to be well predicted by

352 climate models (Fig.2 D), and the outliers are only towards the lower temperature ranges. The

353 observation has narrow box and fewer outliers than the GCM simulations and median is always

354 equal or lower than the GCM simulations (Fig.2D). This simply indicates that GCMs tend to

355 predict more extreme cold temperatures than observation. For seasonal temperature (Fig.2 E and

356 F), most GCMs seem to underestimate observed temperature of cold season, and they show less

357 bias in warm season.

\section{$358 \quad 4.2$ Mean, Standard Deviation, Coefficient of Variation and Relative change}

359 Results of Mean, standard deviation, coefficient of variation and relative change for each GCM

360 and gridded observational data are depicted in figure 3 . The figure $3 \mathrm{a}$ and $3 \mathrm{~b}$ represents the mean

361 along with \pm 1 standard deviation of precipitation and temperature, respectively. It can be observed

362 from the figure that the precipitation distribution of GCMs are strikingly different from that of the

363 gridded observational dataset, usually overestimating the precipitation and underestimating the dry

364 days which can be attributed to drizzle effect in climate models (Beven, 2011). Thus, mean of

365 gridded observational dataset is lower than all the GCMs and accordingly the spread (standard

366 deviation) of dataset. Proximity of mean and standard deviation of each of the GCM is compared

367 to that of observational mean and standard deviation to rank the models (from 1-5) consequently.

368 However, the temperature distribution is in line with gridded observational data with GCM

369 depicting higher spread than the latter. Similarly, mean and standard deviation proximity of the

370 GCM is evaluated against the gridded observational data for ranking. Fig. 3c, CV for precipitation

371 and temperature are specified with blue and red markers, respectively. The far right values (number 
372 21) present results of gridded observational data. For precipitation, $\mathrm{CV}$ for gridded observational 373 dataset is always higher than GCMs whereas 4 models have higher CV than the latter in case of 374 temperature. As mentioned in methodology section, for temperature, CV and RC are calculated 375 using data in Kelvin, since we have non-zero (negative) values in the region. Consequently, models 376 with close proximity to gridded observational dataset would be ranked higher. Relative change 377 shows the inter-annual variations of each variable (Fig. 3d and 3e for precipitation and temperature, 378 respectively). Thus, it might be positive for some years and negative in some other years. The RC 379 for precipitation of gridded observational dataset shows higher spread in boxplot suggesting higher 380 relative change during years than in GCMs whereas it is opposite for temperature wherein the 381 gridded observations have lower relative change than GCMs. The absolute value RC is calculated 382 for each year and then average absolute RC for each GCM and gridded observation is calculated 383 for evaluation. Proximity of CV and RC values of GCMs to gridded observational dataset is used 384 for ranking from 1-5.

\section{$385 \quad 4.3 \quad$ Mann-Kendall test}

386 Trend analysis is performed using Mann-Kendall for gridded observational data and for each

387 model. Values for models are then compared to the value obtained for gridded observational data.

388 Results of trend analysis of precipitation and temperature are tabulated in table 3. In the table,

389 results from Mann-Kendall test on daily precipitation and temperature are shown in the first two 390 columns, followed by decadal change in each variable (using annual data) presented in the last

391 column. Daily results are used for ranking on daily timescale and decadal change is shown to 392 provide more knowledge about the study area. Results from daily Mann-Kendall test on 393 observation dataset show significant positive trend for both precipitation and temperature dataset.

394 Thus for both variables, all the models showing positive trend would be ranked higher relative to 
negative trend ones in the period under consideration. For precipitation, BCC_CSM1_1m, BNU_ESM, GFDL_ESM2G, GFDL-CSM5A-LR, GFDL-CSM5B-LR, and MIROC5 gets the

397 highest ranking of 5 due to positive, significant trend and proximity to statistics of observational 398 dataset and other models are ranked accordingly. Whereas, for temperature, only BCC_CSM1_1 and CanESM2 gets ranking 5 and other models are ranked consequently in comparison to observed

400 statistics. In both cases, i.e. for precipitation and temperature, models with negative trends would 401 receive a least score. It can be observed from the table that many of the models are showing 402 significant trend at $99 \%$ as well ( $p$ values $\leq 0.01)$ for both the variables and only few models do 403 not show any trend in the dataset.

\section{$404 \quad 4.4$ Kolmogorov-Smirnov test (KS-test)}

405 KS-test is performed for gridded observational data and each GCM simulations at all the temporal 406 scales. KS-test statistics are then compared to provide model ranking, on all temporal scales, for 407 both the variables i.e. precipitation and temperature. Results of KS-test are presented in table 4. 408 Since all the simulations, for both precipitation and temperature, rejected null hypothesis i.e. no 409 time series were same at desired alpha, we have considered statistics of the test to evaluate the 410 models in comparison to observational gridded data. The p-values were significantly very small in 411 all the cases to develop a rational comparison of observational data and simulations. Therefore, 412 test statistics are extracted and used for rankings. The statistics close to zero are better 413 representation of the observational dataset and result in lower p-value and thus ranked higher. As 414 can be seen from table 4, for daily precipitation data, BCC_CSM1_1m, CCSM4, CSIRO_Mk3, 415 HadGEM2-CC, HadGEM2-ES, IPSL-CM5A-MR, and NorESM1-M are closest in respect to 416 maximum vertical distance of empirical distribution function to observational gridded data and 417 thus given highest ranking and vice versa for MIROC-ESM and MIROC-ESM-CHEM, with 
418 farthest from observational data for precipitation. Whereas, in case of temperature daily data,

419 GFDL-ESM2M, INMCM4, IPSL-CM5A-LR, IPSL-CM5B-LR, and MRI-CGCM3 are closest as

420 opposed to HadGEM2-ES and MIROC5, being the farthest ones to observational dataset. Same

421 procedure was applied to rank the models on other temporal scales of monthly and seasonal.

\section{$422 \quad 4.5$ Principal Component Analysis (PCA)}

423 The percentage of variance explained by each component in PCA is studied and presented as pareto

424 graph in figure $4 \mathrm{c}$ and $4 \mathrm{~d}$ for precipitation and temperature, respectively. Different components

425 describe different features in each variable and can be used for various purposes. Depending on

426 variance explained (acceptable level of variance explained based on user interest) by each mode

427 of PCA, user can decide on the number of modes to be used in analysis of the data. In this study,

428 for precipitation the first component explained about $10 \%$ of total variance whereas for

429 temperature it was about $89 \%$ of the total variance. The local variance (squared correlation

430 between the GCM simulation and the gridded observational dataset) in first component of PCA is

431 used for ranking the models for both variables. Performance of all the models in accordance to

432 squared correlation with gridded observational data is classified in 5 equal intervals, resulting in a

433 score of 1-5 based on their performance. Results for precipitation and temperature are graphically

434 presented in figure $4 a$ and $4 b$, respectively. Figure $4 a$ represents the various models in relation to

435 averaged gridded observational data in various components of PCA for precipitation and 4b

436 represents the same for temperature. The relative length i.e. distance from center for a particular

437 component (component 1 in this case) of the GCMs defines the relative proximity with the gridded

438 observational data. When the GCM is closer to gridded observational dataset (e.g.

439 BCC_CSM1_1m, CCSM4, and INMCM4 for precipitation), they will receive higher ranking, as

440 compared to ones which are distant from the same (e.g. IPSL-CM5B-LR, MIROC5, MIROC- 
441 ESM, and MIROC-ESM-CHEM). Similarly, for temperature, GCMs (BCC_CSM1_1m, 442 BNU_ESM, CANESM2, CCSM4, GFDL_ESM2G, GFDL_ESM2M, HadGEM2-CC, INMCM4, 443 IPSL-CM5A-LR, IPSL-CM5A-MR, IPSL-CM5B-LR, MRI-CGCM3, and NorESM1-M) closer to 444 gridded observational dataset receives higher ranks and vice-versa (Fig. 4b).Same procedure is 445 performed for other temporal scales of monthly and seasonal.

\subsection{SVD and CCA}

447 Heterogeneous correlation representing maximized covariance between the predictand and 448 predictor is calculated for each GCM using SVD and is used to rank models (table 5). GCMs with

449 higher heterogeneous correlation represents similar properties/attributes with reference to gridded 450 observational data and are more suited for the study area. From table 5, it can be inferred that 451 BCC_CSM1_1, BCC_CSM1_1m, and BNU_ESM presents highest heterogeneous correlation and 452 thus receive the highest ranking for precipitation dataset, with IPSL-CM5A-LR, MIROC-ESM, 453 MIROC-ESM-CHEM, and NorESM1-M receiving the lowest. For temperature, CNRM_CM5, 454 IPSL-CM5A-MR, andMIROC5 are in close proximity to gridded observational dataset (based on 455 heterogeneous correlation) and are ranked highest; whereas HadGEM2-ES, MIROC-ESM, and 456 MIROC-ESM-CHEM are on the other end of ranking.

457 Similarly, CCA results were analyzed based on the similar property of GCMs and gridded 458 observational dataset. In other words, after calculating anomalies of a matrix (GCMs) versus 459 gridded observational data, and calculating PCA of the predictand, predictor canonical spatial 460 function is computed. Values of canonical spatial function (SF) are used to rank models. Models 461 with higher SF values will receive a higher score (table 6). The range of SF across the models is 462 divided in 5 groups and the highest value group will receive a score of 5. For CCA, BCC_CSM1_1, 463 CCSM4, HadGEM2-CC, INMCM4, IPSL-CM5A-MR, and MIROC5 receives the highest ranks 
464 for precipitation dataset, whereas MIROC-ESM and MIROC-ESM-CHEM are ranked lowest. For 465 temperature, BCC_CSM1_1, CanESM2, HadGEM2-CC, IPSL-CM5A-LR, and MRI-CGCM3 are

466 amongst the higher ranked ones, whereas INMCM4, IPSL-CM5B-LR, and MIROC-ESM-CHEM 467 receives the lower ranks.

\section{$468 \quad 4.7$ Cluster Analysis}

469 Results for cluster analysis are presented in figure 5a and $5 \mathrm{~b}$ for precipitation and temperature,

470 respectively. The plots/dendograms are showing different clusters among models and gridded 471 observational data. Dendograms represents both the cluster-subcluster relationships and the order

472 in which clusters are merged or split. Cluster group and linkage distance are important in 473 determining the relative likelihood of models to represent the gridded observational dataset. As it 474 can be interpreted from the dendograms, models have been distributed in several clusters which in

475 turn are connected to each other in the last merged row. In figure 5, the plots show the value of 476 linkage distance in accordance to the merged cluster indices, which are linked in pairs to form 477 binary tree. Linkage distance reflects the degree of difference between branches i.e. longer lines 478 indicate greater difference, principle applied to rank the models. Models which are in the same 479 cluster with the observation (close proximity), are better performing than others. Similarly, the 480 lesser the linkage distance of the model to observation, the higher the performance of the model, 481 and the model receives a better rank. For precipitation (figure 5a), it can be observed that 482 BCC_CSM1_1m (number 2) is in the closest proximity and belongs to same cluster as gridded 483 observational dataset followed by BCC_CSM1_1 (number 1) and CCSM4 (number 5), forming 484 the next closest cluster, and thus would receive highest rankings. The scale of model ranks are 485 classified into 5 classes and ranked on the basis of same. IPSL-CM5B-LR, MIROC-ESM, and 486 MIROC_ESM_CHEM are farthest forming a farthest cluster based on linkage distance and thus 
receives lowest scores for precipitation dataset. For temperature (figure 5b), GFDL_ESM2G,

488 IPSL-CM5A-LR, CCSM4, and IPSL-CM5A-MR are in close proximity to gridded observational

489 dataset (ranked highest), whereas MIROC-ESM, MIROC-ESM-CHEM, BNU_ESM,

490 BCC_CSM1_1m, and MRI-CGCM3 forms the farther clusters and thus ranked lower.

\subsection{Overall Performance}

492 Models performances were assessed in 10 metrics for precipitation and temperature, totaling to 20

493 metrics for each of the temporal scales in consideration, and each model received a score of 1-5 in

494 each metric. Overall ranking, summation of ranks for precipitation and temperature, is provided

495 using all 20 metrics values for each of the temporal scales in consideration. Performance of models

496 on all temporal scales and each metric is depicted in figure 6. From figure 6 and table 7 it can be

497 inferred, based on average overall performance for daily temporal scale, that CCSM4, IPSL-

498 CM5A-MR, INMCM4, IPSL-CM5A-LR, CanESM2, GFDL_ESM2G, BCC_CSM1_1,

499 GFDL_ESM2M, IPSL-CM5B-LR, and MIROC5 are 10 best representative GCMs of the gridded

500 observational dataset (in order of decreasing ranking) in the desired period for the study region.

501 Similar rankings for 10 best representative models for monthly, and seasonal and dataset is

502 provided in figure 6 and table 7. End users can choose to have their own set of models based on

503 utility and time scale in consideration. It can be observed from table 7 that GFDL_ESM2G,

504 CCSM4, IPSL-CM5A-MR, and CanESM2 are among those selected at daily, monthly, summer, 505 and winter temporal scales.

\section{Discussion}

507 The changing climate requires an investigation on understanding of its effects and causes on the

508 environment and hydrological cycle. One of the most used resources for this purpose now-a-days, 
are GCMs which represent the conditions of climate over the globe with predictions for future

510 scenarios. Each of these models has uncertainty associated in their predictions, and as they are

511 large-scale (coarse resolution), they might have different performances in regional scales/finer

512 resolution. Thus, there is a demand to investigate the performance of global models on regional

513 scales. We also intended to study the effects of observation dataset on the GCM selection

514 procedure thus we changed the gridded observational dataset with another gridded observational

515 dataset (Abatzoglou 2013). Similar statistical evaluation and ranking was performed for raw GCM

516 and the changed observational dataset on daily, monthly, and seasonal temporal scale, results are

517 presented in figure 7. It can be noted that the 10 best representative models (with changed gridded

518 observation) includes BCC_CSM1_1, GFDL_ESM2M, CCSM4, GFDL_ESM2G, MIROC5,

519 CanESM2, IPSL-CM5A-MR, IPSL-CM5B-LR, IPSL-CM5A-LR, and MIROC-ESM (in order of

520 decreasing ranking). On comparison, at daily temporal scale, with raw simulation evaluation based

521 on Livneh et al. (2013) gridded observational dataset to that of Abatzoglou (2013) it was found

522 that 9 of the models are represented in both the procedures, with only INMCM4 excluded in later

523 one (which is ranked $11^{\text {th }}$ in changed observational evaluation). It can be concluded that the

524 observational dataset have minimal effect on selection of GCMs which could be attributed to

525 averaging of climatic variables in the study area, making the two observational dataset comparable

526 to each other. Thus it becomes increasingly important to select the observational dataset based on

527 the physical representation in the study area for such analysis.

528 Various statistical methods, temporal scales and dataset have been used to analyze the range of

529 selection possibilities of GCMs in the study area. The advantages of this approach, among others, 530 include easy classification of models, quantitative-based and objective ranking. Hence, less

531 subjectivity is included in the results and users are not expected to be familiar with the study area 
532 in question and thus could be applied in any study area. Moreover, the proposed methods are easy

533 to perform and are handy in understanding the distribution and various statistical properties of the

534 data. It is also suggested in literature (Werner, 2011) to remove multiple models from the same

535 climate institutions so as to deal with the uncertainty associated with them, but that would not

536 suffice the goal of the study in authors' opinion, as we are evaluating the model and not the

537 institution for the capability of prediction. Moreover the GCMs from same institutions have

538 different model setup and thus different simulations from each of them. Also, the results of study

539 have indicated that models from same institution have behaved differently towards the analysis

540 performed in the study.

541 It is also worth exploring the spatial aspects of the GCM selection in comparison to observational

542 dataset. As pointed out in table 1, most of the GCMs have very varied spatial resolution and thus

543 we adopted spatial average approach to evaluate GCMs against observational gridded data in

544 Columbia River Basin. Depending on the scale and intent of the study same procedures can be

545 applied on finer resolution of spatial data, as per availability of fine resolution observations, to

546 compare the two sets. It would be interesting to study the spatial aspects based on elevation and

547 various hydrological regimes in the study area, depending on the intent of the study.

548 CMIP3/CMIP5 simulations have long been used in various studies to evaluate different 549 characteristics of climate change on humans and environment. Characteristics/trends of extreme 550 events have been assessed in various studies (Mallakpour and Villarini, 2015; Najafi and 551 Moazzami, 2015), some of which have used GCM data. The methodology proposed in this study 552 can be applied on daily to multi-day extreme precipitation and temperature data to evaluate GCMs 553 according to their performance in regard to extremes of these variables. Selecting appropriate 554 GCMs would reduce uncertainty of future predictions (in comparison to other GCMs in the study 
region), which is crucial for studying extreme conditions (e.g. floods or droughts), when the least

556 uncertainty is desired. GCM predictions have been used in various studies to detect and attribute

557 hydroclimate changes to human effects (Najafi et al, 2015; Zhang et al. 2013). Eventually,

558 selection of GCMs based on statistical attributes to evaluate various impacts according to the study

559 purpose would help reduce the various uncertainties associated with the larger GCM scale and be

560 helpful in large scale planning and management.

561 Daily dataset from CMIP5 has helped in a more robust analysis, and compare models with more

562 reliability. Metrics used in the present study are among the common statistical methods used in

563 several previous researches, and proved to work fine. Utilizing a variety of methods, each focusing

564 on a certain aspect of performance, along with using two most common climatic parameters brings

565 robustness to the analysis. Different temporal scales are considered in the study for various

566 stakeholder interest and user based analysis. Evaluation of the results of the present study reveals

567 that models generally perform better in temperature than in precipitation and a variable. This is

568 mainly because of the more stable nature of temperature which makes it easier to predict. Models

569 seemed to work differently in various methods. This might infer that models do not have high

570 correlation with each other. Finally, overall scores obtained by GCMs can be used for model

571 averaging or multi-modeling e.g.,(Najafi et al. 2011; Madadgar and Moradkhani 2014). In other

572 words, overall score of GCMs can be standardized and used as the weights applied in weighted

573 averaging. However, since this study is done using spatially averaged data and multi-modeling is

574 usually done at grid scale, it is not suggested to use the scores gathered here for weighted

575 averaging. Instead, one can first downscale all GCMs to a fixed spatial resolution and then apply

576 the methods proposed in this study and use results of each grid to calculate weights for GCMs

577 (Najafi and Moradkhani 2015). 


\section{Summary and Conclusion}

579 Historical data for 20 GCMs from CMIP5, as well as gridded observational data were acquired 580 and accumulated for different temporal scales of daily, monthly and seasonal (summer and winter).

581 GCMs were evaluated with respect to their performance in simulating the climate in Columbia 582 River Basin for historical period. Generally, all GCMs work fairly well in simulating temperature.

583 However for precipitation, GCMs had various behaviors. This is mainly because the average rate

584 of daily variations in precipitation is higher than temperature (e.g. considering two consequent 585 days, one with no precipitation, the other one with heavy rain).

586 Utilizing daily data for 30 years, 10 metrics for 2 different parameters and different temporal scales

587 have helped in robust assessment of models. Several metrics were chosen to investigate various 588 aspects of model statistical properties. All metrics were treated equally and no weights were 589 applied to the results of each metric to decrease the uncertainties. In general, GCMs usually behave 590 differently in various methods, and no fixed methodology is presented to evaluate them. It is up to 591 the research and the purpose of study to conduct a methodology and assess GCMs. The GCMs 592 were also evaluated against different set of gridded observational dataset to study the effect of 593 same on selection procedure. The presented methods can be applied/used for bias correction of the 594 raw GCM data along with any or the statistical and dynamic downscaling method before using 595 them in any study. This would help reduce the uncertainty in the model data. The present research 596 should be considered as qualitative and that could be employed in dealing with GCMs data which 597 in turn is driven by statistical properties of the data itself, which are often used in the field.

\section{Acknowledgement}


599 Partial financial support for this study was provided by the DOE-BPA (cooperative agreement 600 00063182). The authors would also like to acknowledge the World Climate Research Programme's 601 Working Group on Coupled Modelling, which is responsible for CMIP, and we thank the climate 602 modeling groups (listed in table 1 of this paper) for producing and making available their model 603 outputs. For CMIP, the U.S. Department of Energy's Program for Climate Model Diagnosis and 604 Intercomparison provides coordinating support and leads development of software infrastructure 605 in partnership with the Global Organization for Earth System Science Portals. 


\section{References}

607

608

609

610

611

612

613

614

615

616

617

618

619

620

621

622

623

624

625

626

627

628

629

630

631

632

633

634

635

636

Abatzoglou JT (2013) Development of gridded surface meteorological data for ecological applications and modelling. Int J Climatol 33:121-131. doi: 10.1002/joc.3413

Barnston a. G, Ropelewski CF (1992) Prediction of ENSO episodes using canonical correlation analysis. J. Clim. 5:1316-1345.

Belle G, Hughes JP (1984) Nonparametric Tests for Trend in Water Quality. Water Resour Res 20:127-136. doi: 10.1029/WR020i001p00127

Beven, K. J. (2011). Rainfall-runoff modelling: the primer. John Wiley \& Sons.

Bratchell N (1989) Cluster Analysis. 6:105-125.

Bretherton CS, Smith C, Wallace JM (1992) An Intercomparison of Methods for Finding Coupled Patterns in Climate Data. J. Clim. 5:541-560.

Buser CM, Künsch HR, Lüthi D, et al (2009) Bayesian multi-model projection of climate: Bias assumptions and interannual variability. Clim Dyn 33:849-868. doi: 10.1007/s00382-0090588-6

Chiew FHS, Teng J, Vaze J, Kirono DGC (2009) Influence of global climate model selection on runoff impact assessment. J Hydrol 379:172-180. doi: 10.1016/j.jhydrol.2009.10.004

Christensen JH, Kjellström E, Giorgi F, et al (2010) Weight assignment in regional climate models. Clim Res 44:179-194. doi: 10.3354/cr00916

Demirel, M., and H. Moradkhani (in press) Assessing the Impact of CMIP5 Climate MultiModeling on Estimating the Precipitation Seasonality and Timing, Climatic Change.

Deser C, Knutti R, Solomon S, Phillips AS (2012a) Communication of the role of natural variability in future North American climate. Nat Clim Chang 2:775-779. doi: 10.1038/nclimate1562

Deser C, Phillips A, Bourdette V, Teng H (2012b) Uncertainty in climate change projections: The role of internal variability. Clim Dyn 38:527-546. doi: 10.1007/s00382-010-0977-x

Deser C, Phillips AS, Alexander M a., Smoliak B V. (2014) Projecting North American climate over the next 50 years: Uncertainty due to internal variability. J Clim 27:2271-2296. doi: 10.1175/JCLI-D-13-00451.1

Fowler HJ, Blenkinsop S, Tebaldi C (2007) Review: Linking climate change modelling to impacts studies: recent advances in downscaling techniques for hydrological modelling. Int J Climatol 27:1547-1578. doi: 10.1002/joc 
Govindarajulu Z (1992) Rank Correlation Methods (5th ed.). Technometrics 34:108. doi: $10.1080 / 00401706.1992 .10485252$

639

640

641

642

643

644

645

646

647

648

649

650

651

652

653

654

655

656

657

658

659

660

661

662

663

664

665

666

667

668

Hawkins E, Sutton R (2011) The potential to narrow uncertainty in projections of regional precipitation change. Clim Dyn 37:407-418. doi: 10.1007/s00382-010-0810-6

Hintze JL, Nelson RD (1998) Violin plots: A box plot-density trace synergism. Am. Stat. 52:181184.

Huth R, Pokorn L (2004) Parametric versus non-parametric estimates of climatic trends. Theor Appl Climatol 77:107-112. doi: 10.1007/s00704-003-0026-3

Johnson F, Westra S, Sharma A, Pitman AJ (2011) An assessment of GCM skill in simulating persistence across multiple time scales. J Clim 24:3609-3623. doi: 10.1175/2011JCLI3732.1

Jost G, Moore RD, Menounos B, Wheate R (2012) Quantifying the contribution of glacier runoff to streamflow in the upper Columbia River Basin, Canada. Hydrol Earth Syst Sci 16:849860. doi: 10.5194/hess-16-849-2012

Livneh B, Rosenberg EA, Lin C, et al (2013) A Long-Term Hydrologically Based Dataset of Land Surface Fluxes and States for the Conterminous United States: Update and Extensions*. J Clim 26:9384-9392. doi: 10.1175/JCLI-D-12-00508.1

Madadgar S, Moradkhani H (2014) Improved Bayesian multimodeling: Integration of copulas and Bayesian model averaging. Water Resour Res 50:9586-9603. doi: 10.1002/2014WR015965.Received

Mallakpour, I., Villarini, G. (2015). The changing nature of flooding across the central United States. Nature Climate Change, 5(3), 250-254.

Maxino CC, McAvaney BJ, Pitman AJ, Perkins SE (2008) Ranking the AR4 climate models over the Murray-Darling Basin using simulated maximum temperature, minimum temperature and precipitation. Int J Climatol 28:1097-1112. doi: 10.1002/joc

Miao C, Duan Q, Yang L, Borthwick AGL (2012) On the Applicability of Temperature and Precipitation Data from CMIP3 for China. PLoS One 7:1-10. doi: 10.1371/journal.pone.0044659

Moradkhani H, Baird RG, Wherry S a. (2010) Assessment of climate change impact on floodplain and hydrologic ecotones. J Hydrol 395:264-278. doi: 10.1016/j.jhydrol.2010.10.038

Moradkhani H, Meier M (2010) Long-Lead Water Supply Forecast Using Large-Scale Climate Predictors and Independent Component Analysis. J Hydrol Eng 15:744-762. doi: 10.1061/(ASCE)HE.1943-5584.0000246 
Najafi, M. R., Moazami, S. (2015). Trends in total precipitation and magnitude-frequency of extreme precipitation in Iran, 1969-2009. International Journal of Climatology.

Najafi MR, Moradkhani H (2015) Multi-model ensemble analysis of runoff extremes for climate change impact assessments. J Hydrol 525:352-361. doi: 10.1016/j.jhydrol.2015.03.045

Najafi MR, Moradkhani H, Jung IW (2011) Assessing the uncertainties of hydrologic model selection in climate change impact studies. Hydrol Process 25:2814-2826. doi: 10.1002/hyp. 8043

Najafi, M. R., Zwiers, F. W., \& Gillett, N. P. (2015). Attribution of Arctic temperature change to greenhouse-gas and aerosol influences. Nature Climate Change.

Nishii K, Miyasaka T, Nakamura H, et al (2012) Relationship of the Reproducibility of Multiple Variables among Global Climate Models. J Meteorol Soc Japan 90A:87-100. doi: 10.2151/jmsj.2012-A04

Önol B, Bozkurt D, Turuncoglu UU, et al (2014) Evaluation of the twenty-first century RCM simulations driven by multiple GCMs over the Eastern Mediterranean-Black Sea region. Clim Dyn 42:1949-1965. doi: 10.1007/s00382-013-1966-7

Pierce DW, Barnett TP, Santer BD, Gleckler PJ (2009) Selecting global climate models for regional climate change studies. Proc Natl Acad Sci U S A 106:8441-8446. doi: 10.1073/pnas.0900094106

Rana A, Uvo CB, Bengtsson L, Sarthi PP (2012) Trend analysis for rainfall in Delhi and Mumbai, India. Clim Dyn 38:45-56. doi: 10.1007/s00382-011-1083-4

Rana A, Madan S, Bengtsson L (2013) Performance Evaluation of Regional Climate Models (RCMs) in determining precipitation characteristics for Göteborg, Sweden. Hydrology

Pincus R, Batstone CP, Patrick Hofmann RJ, et al (2008) Evaluating the present-day simulation of clouds, precipitation, and radiation in climate models. J Geophys Res Atmos 113:1-10. doi: 10.1029/2007JD009334

Raju K, Nagesh Kumar D (2014) Ranking of global climate models for India using multicriterion analysis. Clim Res 60:103-117. doi: 10.3354/cr01222 Research. doi:10.2166/nh.2013.160

Rana, A., and H. Moradkhani (2015) Spatial, temporal and frequency based climate change assessment in Columbia River Basin using multi downscaled-Scenarios, Climate Dynamics, DOI: $10.1007 / \mathrm{s} 00382-015-2857-\mathrm{x}$.

Rupp DE, Abatzoglou JT, Hegewisch KC, Mote PW (2013) Evaluation of CMIP5 20th century climate simulations for the Pacific Northwest USA. J Geophys Res Atmos 118:10884-10906. doi: 10.1002/jgrd.50843 
Samadi S, Wilson C a ME, Moradkhani H (2013) Uncertainty analysis of statistical downscaling models using Hadley Centre Coupled Model. Theor Appl Climatol 114:673-690. doi: $10.1007 / \mathrm{s} 00704-013-0844-\mathrm{x}$

Taylor KE, Stouffer RJ, Meehl G a. (2012) An overview of CMIP5 and the experiment design. Bull Am Meteorol Soc 93:485-498. doi: 10.1175/BAMS-D-11-00094.1

Unal Y, Kindap T, Karaca M (2003) Redefining the climate zones of Turkey using cluster analysis. Int J Climatol 23:1045-1055. doi: 10.1002/joc.910

Wallace JM, Smith C, Bretherton CS (1992) Singular Value Decomposition of Wintertime Sea Surface Temperature and 500-mb Height Anomalies. J. Clim. 5:561-576.

Wang D, Hagen SC, Alizad K (2013) Climate change impact and uncertainty analysis of extreme rainfall events in the Apalachicola River basin, Florida. J Hydrol 480:125-135. doi: 10.1016/j.jhydrol.2012.12.015

Werner AT (2011) BCSD Downscaled Transient Climate Projections for Eight Select GCMs over British Columbia, Canada. Pacific Climate Impacts Consortium. University of Victoria. Victoria. BC. 63 pp.

Wilks DS (2011) Statistical methods in the atmospheric sciences (Vol. 100). Academic press.

Wójcik R (2014) Reliability of CMIP5 GCM simulations in reproducing atmospheric circulation over europe and the north atlantic: A statistical downscaling perspective. Int $\mathrm{J}$ Climatol 732:714-732. doi: 10.1002/joc.4015

Woldemeskel FM, Sharma a., Sivakumar B, Mehrotra R (2012) An error estimation method for precipitation and temperature projections for future climates. J Geophys Res Atmos 117:113. doi: $10.1029 / 2012 J D 018062$

Zhang, X., Wan, H., Zwiers, F. W., Hegerl, G. C., \& Min, S. K. (2013). Attributing intensification of precipitation extremes to human influence. Geophysical Research Letters, 40(19), 52525257. 
730 Table 1.Models used in this study and their characteristics

\begin{tabular}{|c|c|c|c|c|}
\hline S.No. & Model & Center & $\begin{array}{c}\text { Atm. } \\
\text { Resolution } \\
\text { (Lon x Lat) } \\
\end{array}$ & $\begin{array}{l}\text { Vertical } \\
\text { levels in } \\
\text { Atm. }\end{array}$ \\
\hline 1 & bcc-csm1-1 & Beijing Climate Center, China Meteorological Administration & $2.8 \times 2.8$ & 26 \\
\hline 2 & bcc-csm1-1-m & Beijing Climate Center, China Meteorological Administration & $1.12 \times 1.12$ & 26 \\
\hline 3 & BNU-ESM & $\begin{array}{c}\text { College of Global Change and Earth System Science, Beijing } \\
\text { Normal University, China }\end{array}$ & $2.8 \times 2.8$ & 26 \\
\hline 4 & CanESM2 & Canadian Centre for Climate Modeling and Analysis & $2.8 \times 2.8$ & 35 \\
\hline 5 & CCSM4 & National Center of Atmospheric Research, USA & $1.25 \times 0.94$ & 26 \\
\hline 6 & CNRM-CM5 & National Centre of Meteorological Research, France & $1.4 \times 1.4$ & 31 \\
\hline 7 & CSIRO-Mk3-6-0 & $\begin{array}{c}\text { Commonwealth Scientific and Industrial Research } \\
\text { Organization/ Queensland Climate Change Centre of } \\
\text { Excellence, Australia }\end{array}$ & $1.8 \times 1.8$ & 18 \\
\hline 8 & GFDL-ESM2G & NOAA Geophysical Fluid Dynamics Laboratory, USA & $2.5 \times 2.0$ & 48 \\
\hline 9 & GFDL-ESM2M & NOAA Geophysical Fluid Dynamics Laboratory, USA & $2.5 \times 2.0$ & 48 \\
\hline 10 & HadGEM2-CC & Met Office Hadley Center, UK & $1.88 \times 1.25$ & 60 \\
\hline 11 & HadGEM2-ES & Met Office Hadley Center, UK & $1.88 \times 1.25$ & 38 \\
\hline 12 & INMCM4 & Institute for Numerical Mathematics, Russia & $2.0 \times 1.5$ & 21 \\
\hline 13 & IPSL-CM5A-LR & Institut Pierre Simon Laplace, France & $3.75 \times 1.8$ & 39 \\
\hline 14 & IPSL-CM5A-MR & Institut Pierre Simon Laplace, France & $2.5 \times 1.25$ & 39 \\
\hline 15 & IPSL-CM5B-LR & Institut Pierre Simon Laplace, France & $3.75 \times 1.8$ & 39 \\
\hline 16 & MIROC5 & $\begin{array}{l}\text { Atmosphere and Ocean Research Institute (The University of } \\
\text { Tokyo), National Institute for Environmental Studies, and } \\
\text { Japan Agency for Marine-Earth Science and Technology }\end{array}$ & $1.4 \times 1.4$ & 40 \\
\hline 17 & MIROC-ESM & $\begin{array}{l}\text { Japan Agency for Marine-Earth Science and Technology, } \\
\text { Atmosphere and Ocean Research Institute (The University of } \\
\text { Tokyo), and National Institute for Environmental Studies }\end{array}$ & $2.8 \times 2.8$ & 80 \\
\hline 18 & $\begin{array}{l}\text { MIROC-ESM- } \\
\text { CHEM }\end{array}$ & $\begin{array}{l}\text { Japan Agency for Marine-Earth Science and Technology, } \\
\text { Atmosphere and Ocean Research Institute (The University of } \\
\text { Tokyo), and National Institute for Environmental Studies }\end{array}$ & $2.8 \times 2.8$ & 80 \\
\hline 19 & MRI-CGCM3 & Meteorological Research Institute, Japan & $1.1 \times 1.1$ & 48 \\
\hline 20 & NorESM1-M & Norwegian Climate Center, Norway & $2.5 \times 1.9$ & 26 \\
\hline
\end{tabular}


737 Table 2. Summary of data types/characteristics used in each method

\begin{tabular}{|l|c|c|}
\hline Metric & Precipitation & Temperature \\
\hline Mean & SA* & SA \\
\hline Std dev & SA & SA \\
\hline CV & SA & SA, Data in Kelvin \\
\hline Mann-Kendall & SA, Annual timescale & SA, Data in Kelvin, Annual timescale \\
\hline KS-test & SA & SA \\
\hline PCA & SA, Stdz** & SA, Stdz \\
\hline SVD & SA, Stdz & SA, Stdz \\
\hline CCA & SA, Stdz & SA, Stdz \\
\hline Cluster & SA, Stdz & SA, Stdz \\
\hline * SA: Spatially averaged over the study area \\
** Stdz: Standardized data
\end{tabular}

Table 3. Mann-Kendall test statistics of both precipitation and temperature data (Values in bold are significant at 95\%). The last two columns indicate 30-year mean change of annual precipitation and temperature for each model.

\begin{tabular}{|c|l|c|c|c|c|c|c|}
\hline \multirow{2}{*}{ S. No. } & \multirow{2}{*}{ Model } & \multicolumn{2}{|c|}{ Precipitation } & \multicolumn{2}{c|}{ Temperature } & \multicolumn{2}{c|}{$\begin{array}{c}\text { 30-year mean change of } \\
\text { annual datasets }\end{array}$} \\
\cline { 3 - 8 } & & Z-Value & P-Value & Z-Value & P-Value & Prec. $(\boldsymbol{\%})$ & Temp. $\left({ }^{\circ}\right.$ C) \\
\hline 1 & BCC_CSM1_1 & $\mathbf{- 2 . 1 6 9}$ & $\mathbf{0 . 0 3 0}$ & $\mathbf{3 . 3 1 8}$ & $\mathbf{0 . 0 0 1}$ & -6.44 & 1.07 \\
\hline 2 & BCC_CSM1_1m & $\mathbf{3 . 5 8 9}$ & $\mathbf{0 . 0 0 0}$ & 1.176 & 0.239 & 12.29 & 0.14 \\
\hline 3 & BNU_ESM & $\mathbf{2 . 0 5 7}$ & $\mathbf{0 . 0 4 0}$ & $\mathbf{2 . 5 0 6}$ & $\mathbf{0 . 0 1 2}$ & 5.40 & 0.70 \\
\hline 4 & CanESM2 & -1.651 & 0.099 & $\mathbf{3 . 9 1 6}$ & $\mathbf{0 . 0 0 0}$ & -5.44 & 1.18 \\
\hline 5 & CCSM4 & 0.422 & 0.673 & $\mathbf{5 . 0 0 9}$ & $\mathbf{0 . 0 0 0}$ & 4.07 & 1.59 \\
\hline 6 & CNRM_CM5 & 0.658 & 0.510 & $\mathbf{4 . 1 5 1}$ & $\mathbf{0 . 0 0 0}$ & 0.70 & 0.86 \\
\hline 7 & CSIRO_MK3 & 1.910 & 0.056 & 1.073 & 0.283 & 7.46 & 0.14 \\
\hline 8 & GFDL_ESM2G & $\mathbf{2 . 2 3 2}$ & $\mathbf{0 . 0 2 6}$ & $\mathbf{2 . 3 8 1}$ & $\mathbf{0 . 0 1 7}$ & 6.12 & 0.57 \\
\hline 9 & GFDL_ESM2M & $\mathbf{- 2 . 1 5 1}$ & $\mathbf{0 . 0 3 2}$ & 1.254 & 0.210 & -4.16 & 0.08 \\
\hline 10 & HadGEM2-CC & 1.281 & 0.200 & 0.372 & 0.710 & 3.66 & 0.07 \\
\hline 11 & HadGEM2-ES & -0.598 & 0.550 & 0.913 & 0.361 & -0.75 & 0.37 \\
\hline 12 & INMCM4 & -0.034 & 0.973 & $\mathbf{4 . 2 6 8}$ & $\mathbf{0 . 0 0 0}$ & 0.42 & 0.98 \\
\hline 13 & IPSL-CM5A-LR & $\mathbf{3 . 4 8 4}$ & $\mathbf{0 . 0 0 0}$ & 1.558 & 0.119 & 9.71 & 0.32 \\
\hline 14 & IPSL-CM5A-MR & $\mathbf{- 2 . 2 2 9}$ & $\mathbf{0 . 0 2 6}$ & $\mathbf{2 . 4 4 8}$ & $\mathbf{0 . 0 1 4}$ & -2.51 & 0.67 \\
\hline 15 & IPSL-CM5B-LR & $\mathbf{4 . 6 0 5}$ & $\mathbf{0 . 0 0 0}$ & -0.058 & 0.954 & 8.36 & 0.34 \\
\hline 16 & MIROC5 & $\mathbf{2 . 3 2 5}$ & $\mathbf{0 . 0 2 0}$ & $\mathbf{4 . 4 7 0}$ & $\mathbf{0 . 0 0 0}$ & 6.32 & 1.27 \\
\hline 17 & MIROC-ESM & -1.051 & 0.293 & $\mathbf{6 . 8 1 9}$ & $\mathbf{0 . 0 0 0}$ & -1.24 & 1.81 \\
\hline 18 & MIROC-ESM-CHEM & 0.775 & 0.438 & $\mathbf{2 . 4 6 6}$ & $\mathbf{0 . 0 1 4}$ & 1.28 & 0.30 \\
\hline 19 & MRI-CGCM3 & 0.923 & 0.356 & 0.383 & 0.702 & 1.91 & 0.07 \\
\hline 20 & NorESM1-M & $\mathbf{- 2 . 6 2 9}$ & $\mathbf{0 . 0 0 9}$ & 0.980 & 0.327 & -4.67 & -0.09 \\
\hline
\end{tabular}




\begin{tabular}{|l|l|l|l|l|l|l|l|}
\hline 21 & Gridded observational Data & $\mathbf{3 . 0 3 9}$ & $\mathbf{0 . 0 0 2}$ & $\mathbf{3 . 4 3 1}$ & $\mathbf{0 . 0 0 1}$ & 6.95 & 0.61 \\
\hline
\end{tabular}

743 Table 4. Statistics calculated in the two-sample Kolmogorov-Smirnov test. 95\% confidence interval and 744 unequal tail condition are taken as the assumptions in all cases. Smaller statistics value represent less 745 difference in cumulative density function of model and observation, and thus is of more interest.

\begin{tabular}{|c|l|c|c|}
\hline S. No. & \multicolumn{1}{|c|}{ Model } & Precipitation & Temperature \\
\hline 1 & BCC-CSM1-1 & 0.220 & 0.186 \\
\hline 2 & BCC-CSM1-1m & 0.130 & 0.189 \\
\hline 3 & BNU-ESM & 0.291 & 0.180 \\
\hline 4 & CanESM2 & 0.135 & 0.251 \\
\hline 5 & CCSM4 & 0.170 & 0.223 \\
\hline 6 & CNRM-CM5 & 0.262 & 0.160 \\
\hline 7 & CSIRO-Mk3 & 0.168 & 0.176 \\
\hline 8 & GFDL-ESM2G & 0.230 & 0.212 \\
\hline 9 & GFDL-ESM2M & 0.289 & 0.145 \\
\hline 10 & HadGEM2-CC & 0.142 & 0.238 \\
\hline 11 & HadGEM2-ES & 0.137 & 0.245 \\
\hline 12 & INMCM4 & 0.377 & 0.121 \\
\hline 13 & IPSL-CM5A-LR & 0.236 & 0.144 \\
\hline 14 & IPSL-CM5A-MR & 0.176 & 0.178 \\
\hline 15 & IPSL-CM5B-LR & 0.179 & 0.143 \\
\hline 16 & MIROC5 & 0.224 & 0.272 \\
\hline 17 & MIROC-ESM & 0.373 & 0.236 \\
\hline 18 & MIROC-ESM-CHEM & 0.371 & 0.239 \\
\hline 19 & MRI-CGCM3 & 0.307 & 0.100 \\
\hline 20 & NorESM1-M & 0.179 & 0.185 \\
\hline
\end{tabular}


756 Table 5. Heterogeneous correlation calculated for each GCM by SVD

\begin{tabular}{|c|l|c|c|}
\hline \multirow{2}{*}{ S. No. } & \multirow{2}{*}{ Model } & \multicolumn{2}{|c|}{ SVD } \\
\cline { 3 - 4 } & & Precipitation & Temperature \\
\hline 1 & BCC-CSM1-1 & 0.090 & 0.824 \\
\hline 2 & BCC-CSM1-1m & 0.127 & 0.800 \\
\hline 3 & BNU-ESM & 0.107 & 0.823 \\
\hline 4 & CanESM2 & 0.057 & 0.843 \\
\hline 5 & CCSM4 & 0.100 & 0.830 \\
\hline 6 & CNRM-CM5 & 0.071 & 0.862 \\
\hline 7 & CSIRO-Mk3 & 0.087 & 0.859 \\
\hline 8 & GFDL-ESM2G & 0.067 & 0.845 \\
\hline 9 & GFDL-ESM2M & 0.051 & 0.836 \\
\hline 10 & HadGEM2-CC & 0.076 & 0.846 \\
\hline 11 & HadGEM2-ES & 0.064 & 0.775 \\
\hline 12 & INMCM4 & 0.071 & 0.822 \\
\hline 13 & IPSL-CM5A-LR & 0.024 & 0.833 \\
\hline 14 & IPSL-CM5A-MR & 0.079 & 0.842 \\
\hline 15 & IPSL-CM5B-LR & 0.058 & 0.820 \\
\hline 16 & MIROC5 & 0.053 & 0.858 \\
\hline 17 & MIROC-ESM & -0.025 & 0.687 \\
\hline 18 & MIROC-ESM-CHEM & -0.016 & 0.683 \\
\hline 19 & MRI-CGCM3 & 0.053 & 0.816 \\
\hline 20 & NorESM1-M & 0.038 & 0.816 \\
\hline & & & \\
\hline
\end{tabular}


769 Table 6. Canonical spatial function (SF) calculated by CCA for each GCM

\begin{tabular}{|c|l|c|c|}
\hline \multirow{2}{*}{ S. No. } & \multirow{2}{*}{ Model } & \multicolumn{2}{|c|}{ CCA } \\
\cline { 3 - 4 } & & Precipitation & Temperature \\
\hline 1 & BCC-CSM1-1 & 0.248 & 0.431 \\
\hline 2 & BCC-CSM1-1m & 0.183 & 0.150 \\
\hline 3 & BNU-ESM & 0.170 & 0.052 \\
\hline 4 & CanESM2 & 0.129 & 0.099 \\
\hline 5 & CCSM4 & 0.229 & 0.043 \\
\hline 6 & CNRM-CM5 & 0.146 & 0.043 \\
\hline 7 & CSIRO-Mk3 & 0.130 & 0.165 \\
\hline 8 & GFDL-ESM2G & 0.113 & 0.029 \\
\hline 9 & GFDL-ESM2M & 0.146 & 0.042 \\
\hline 10 & HadGEM2-CC & 0.260 & 0.125 \\
\hline 11 & HadGEM2-ES & 0.136 & 0.077 \\
\hline 12 & INMCM4 & 0.221 & -0.180 \\
\hline 13 & IPSL-CM5A-LR & -0.024 & 0.101 \\
\hline 14 & IPSL-CM5A-MR & 0.293 & 0.038 \\
\hline 15 & IPSL-CM5B-LR & 0.024 & -0.179 \\
\hline 16 & MIROC5 & 0.212 & 0.040 \\
\hline 17 & MIROC-ESM & -0.082 & -0.105 \\
\hline 18 & MIROC-ESM-CHEM & -0.088 & -0.151 \\
\hline 19 & MRI-CGCM3 & 0.172 & 0.107 \\
\hline 20 & NorESM1-M & -0.005 & 0.073 \\
\hline & & & \\
\hline
\end{tabular}

771 Table 7. List of top 10 models from 20 GCMs in the study for various temporal scales in order of decreasing 772 ranking. (Models in bold are common to all temporal scales)

\begin{tabular}{|l|l|l|l|l|}
\hline No. & \multicolumn{1}{|c|}{ Daily } & \multicolumn{1}{c|}{ Monthly } & \multicolumn{1}{c|}{ Seasonal- Summers } & \multicolumn{1}{c|}{ Seasonal- Winters } \\
\hline 1 & CCSM4 & IPSL-CM5A-MR & BCC_CSM1_1 & INMCM4 \\
\hline 2 & IPSL-CM5A-MR & BCC_CSM1_1m & GFDL_ESM2G & CanESM2 \\
\hline 3 & INMCM4 & CSIRO_MK3 & CanESM2 & CCSM4 \\
\hline 4 & IPSL-CM5A-LR & INMCM4 & BCC_CSM1_1m & IPSL-CM5B-LR \\
\hline 5 & CanESM2 & IPSL-CM5A-LR & IPSL-CM5A-MR & MIROC5 \\
\hline 6 & GFDL_ESM2G & CCSM4 & MRI-CGCM3 & GFDL_ESM2M \\
\hline 7 & BCC_CSM1_1 & CNRM_CM5 & CNRM_CM5 & IPSL-CM5A-MR \\
\hline 8 & GFDL_ESM2M & CanESM2 & CCSM4 & BCC_CSM1_1 \\
\hline 9 & IPSL-CM5B-LR & MRI-CGCM3 & HadGEM2-CC & BCC_CSM1_1m \\
\hline 10 & MIROC5 & GFDL_ESM2G & IPSL-CM5A-LR & GFDL_ESM2G \\
\hline
\end{tabular}

773

774 


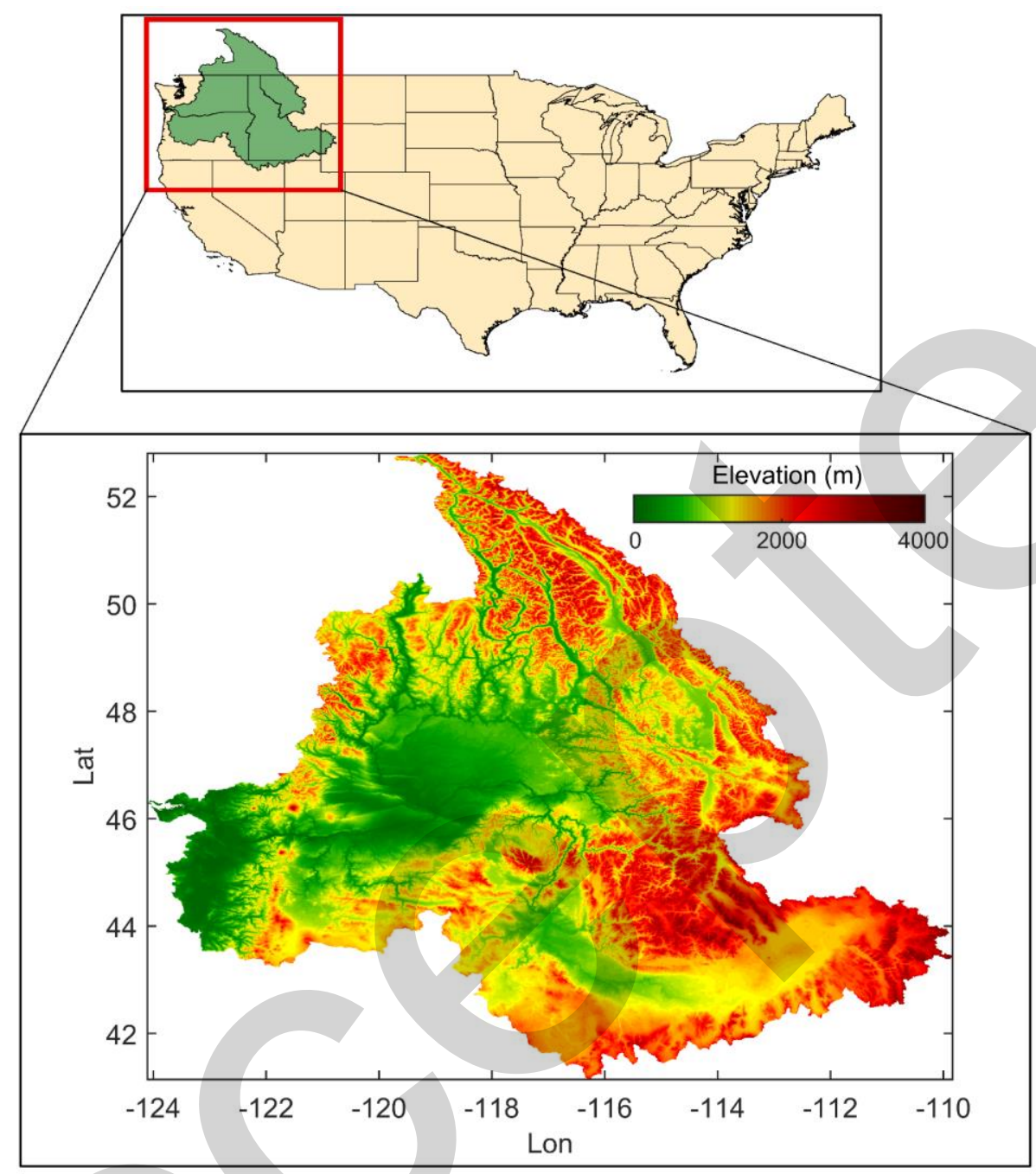

777 Figure 1. Study Area, Columbia River Basin (CRB) in the Pacific North-West USA 

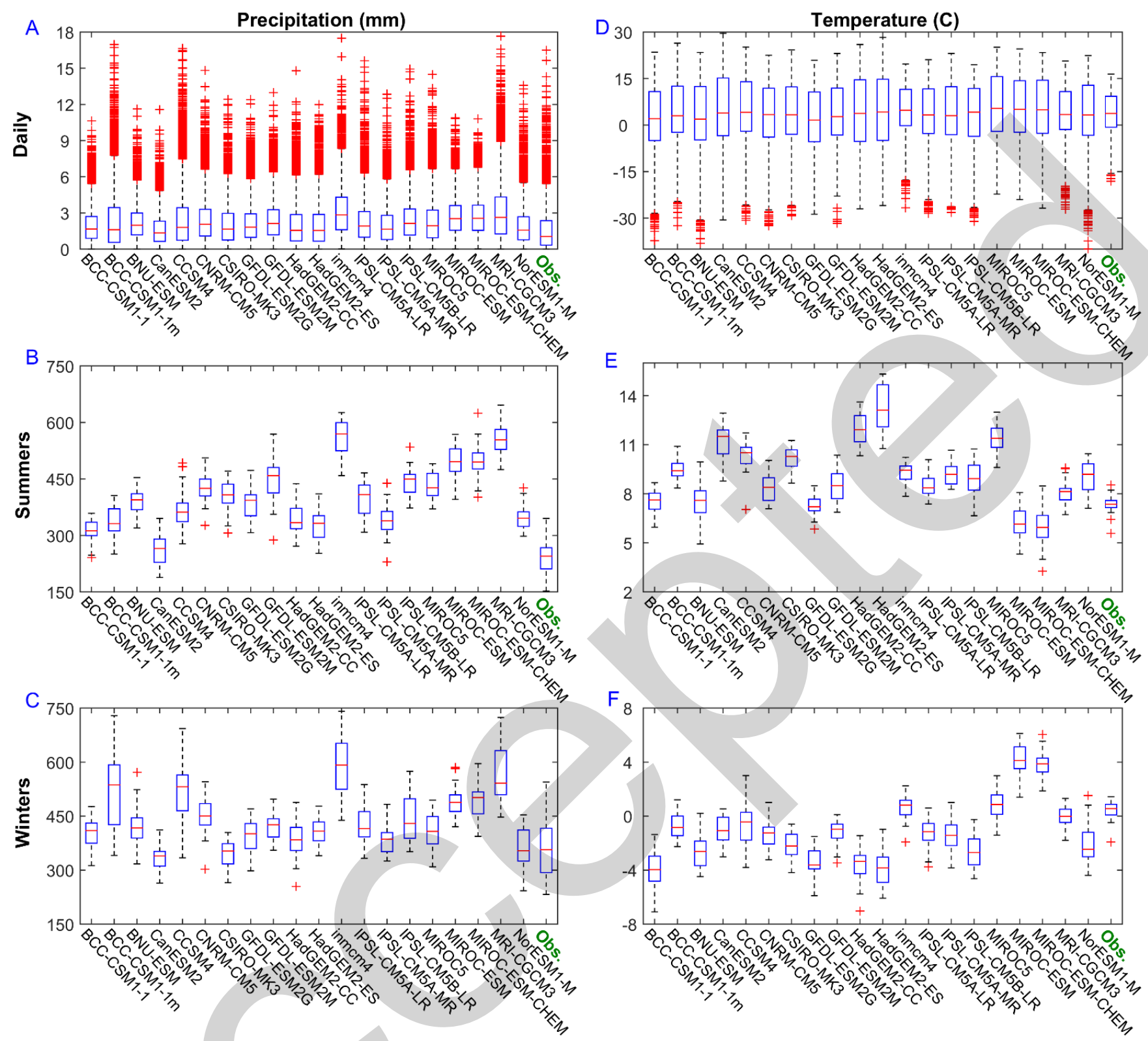

Figure 2. Boxplots depicting the distribution of precipitation and temperature in models and observation. Precipitation is plotted on the left, and temperature on the right. Daily, and seasonal data distribution are plotted from top to bottom, respectively. In each plot, observation is plotted after all GCMs, and is specified by green label. 

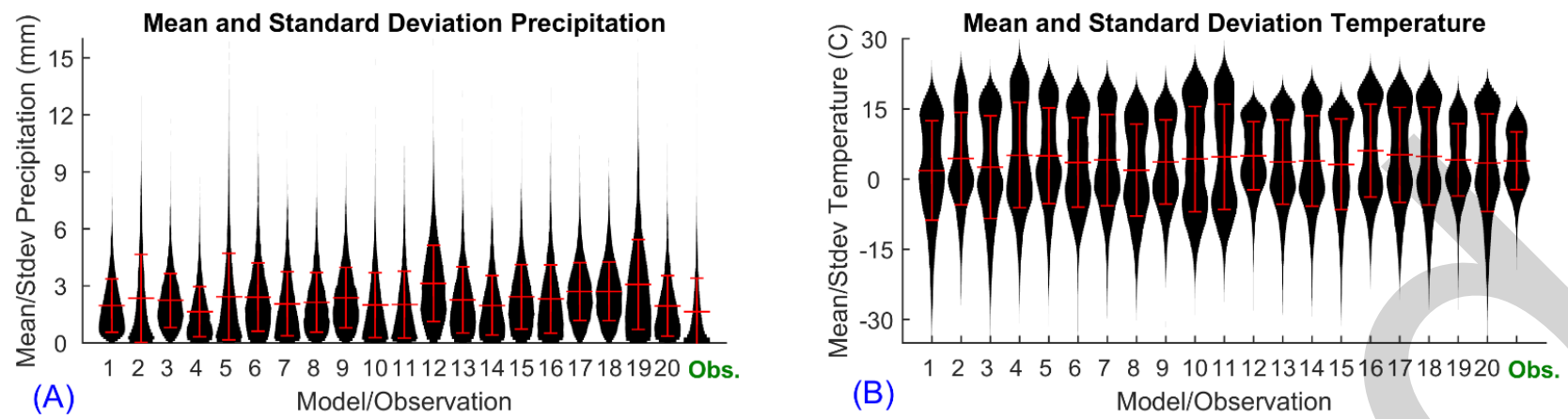

(C)
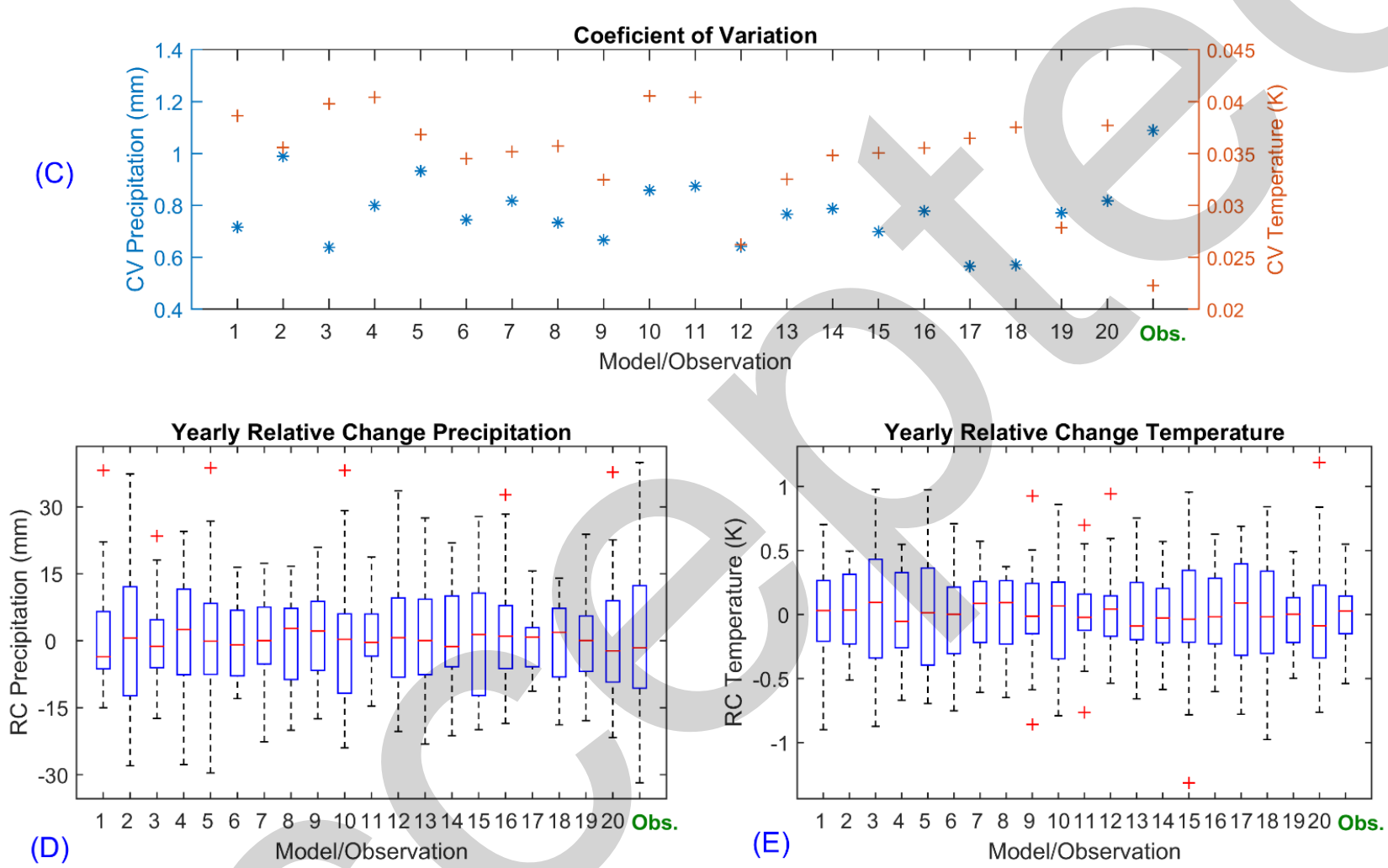

Figure 3. (a) Mean and (+/- 1) Standard Deviation of precipitation in models and observation (Violon Plot), (b) Mean and (+/-1) Standard Deviation of temperature in models and observation (Violon Plot), (c) Values of CV for precipitation and temperature. Precipitation is depicted using '*' with values on the left y-axis; whereas temperature is depicted using ' + ' with values on the right y-axis, (d) Box plot of $\mathrm{RC}$ for precipitation in all the 30 years of data analysis, and (e) Box plot of $\mathrm{RC}$ for temperature in all the 30 years of data analysis. Model numbers on x-axis are the same as those provided in table 1. 
A
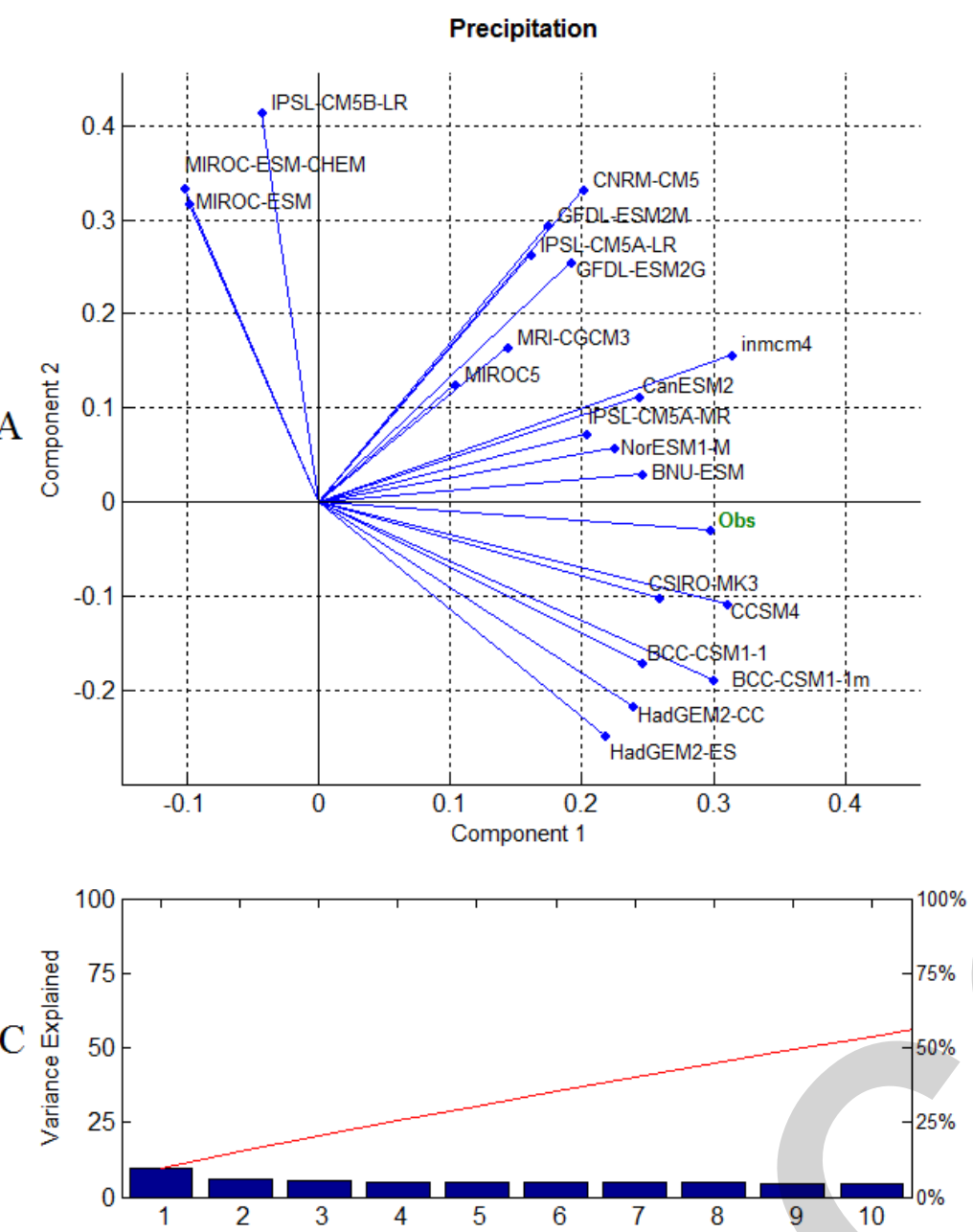

Principal Component

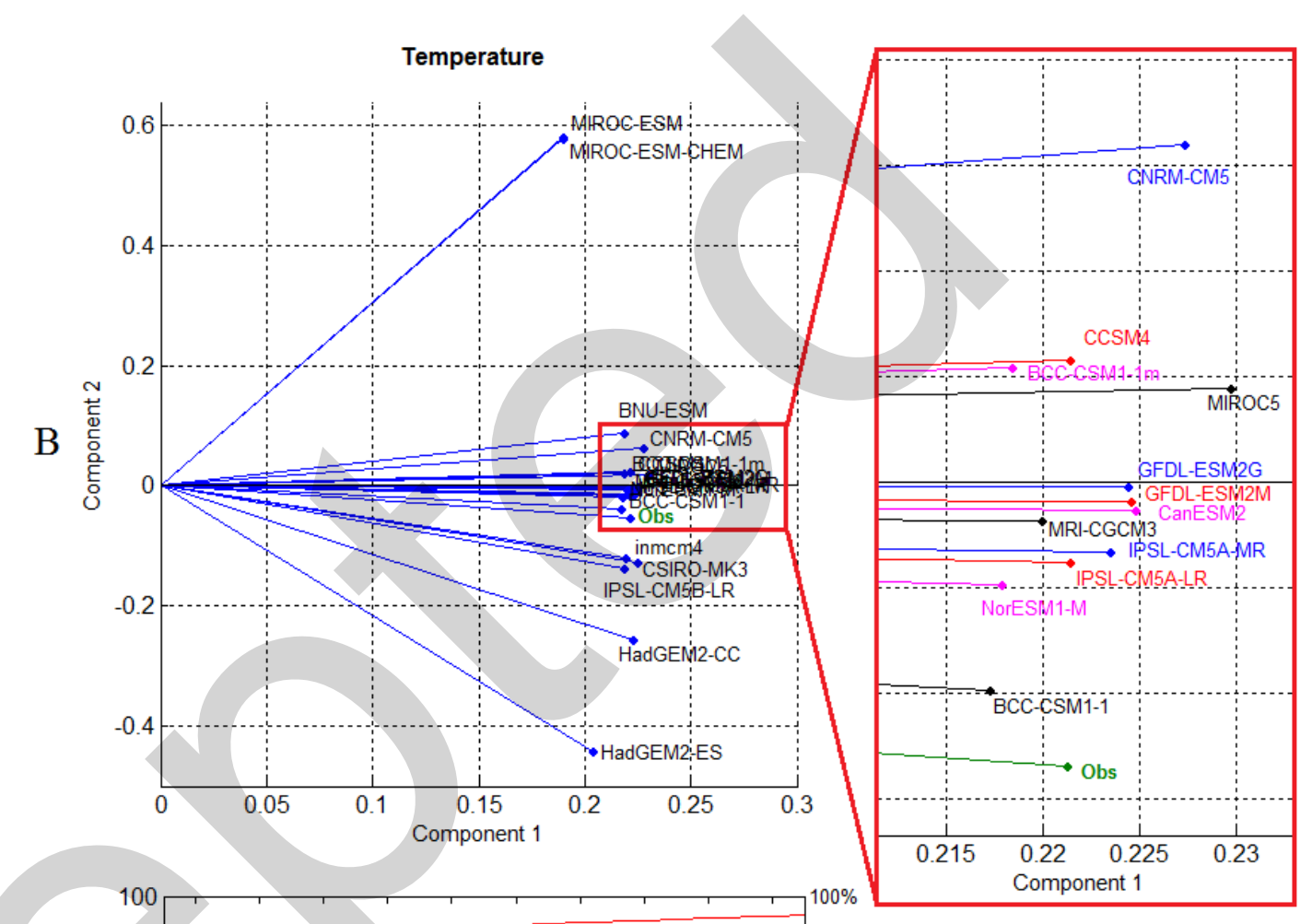

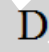

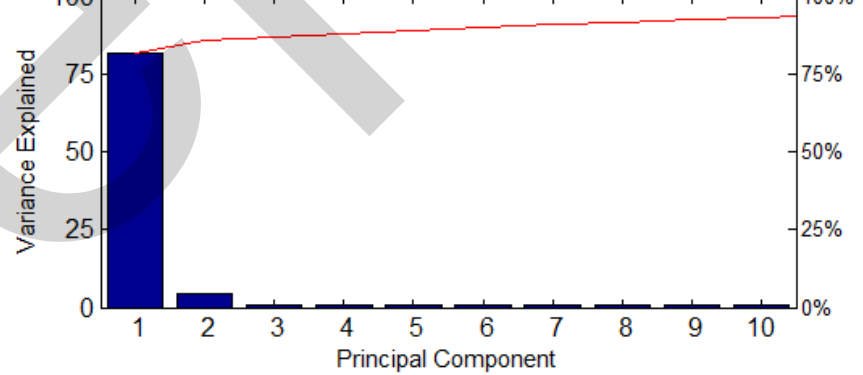

Figure 4. (a) Plots of relative distance of GCMs and gridded observational data on particular component of PCA for precipitation. Relative distance of GCMs on the axis of principal components compared to gridded observational data represents their proximity to observation, and is used to rank GCMs (the lower the distance, the closer the GCM predictions are to the gridded observational data), (b) Same as (a) for temperature, (c) Pareto plot (individual variance explained by principal components are represented in descending order by bars, and the cumulative total of variance is represented by the line) for total variance explained for a particular PCA component for precipitation, and (d) Same as (c) for temperature. 

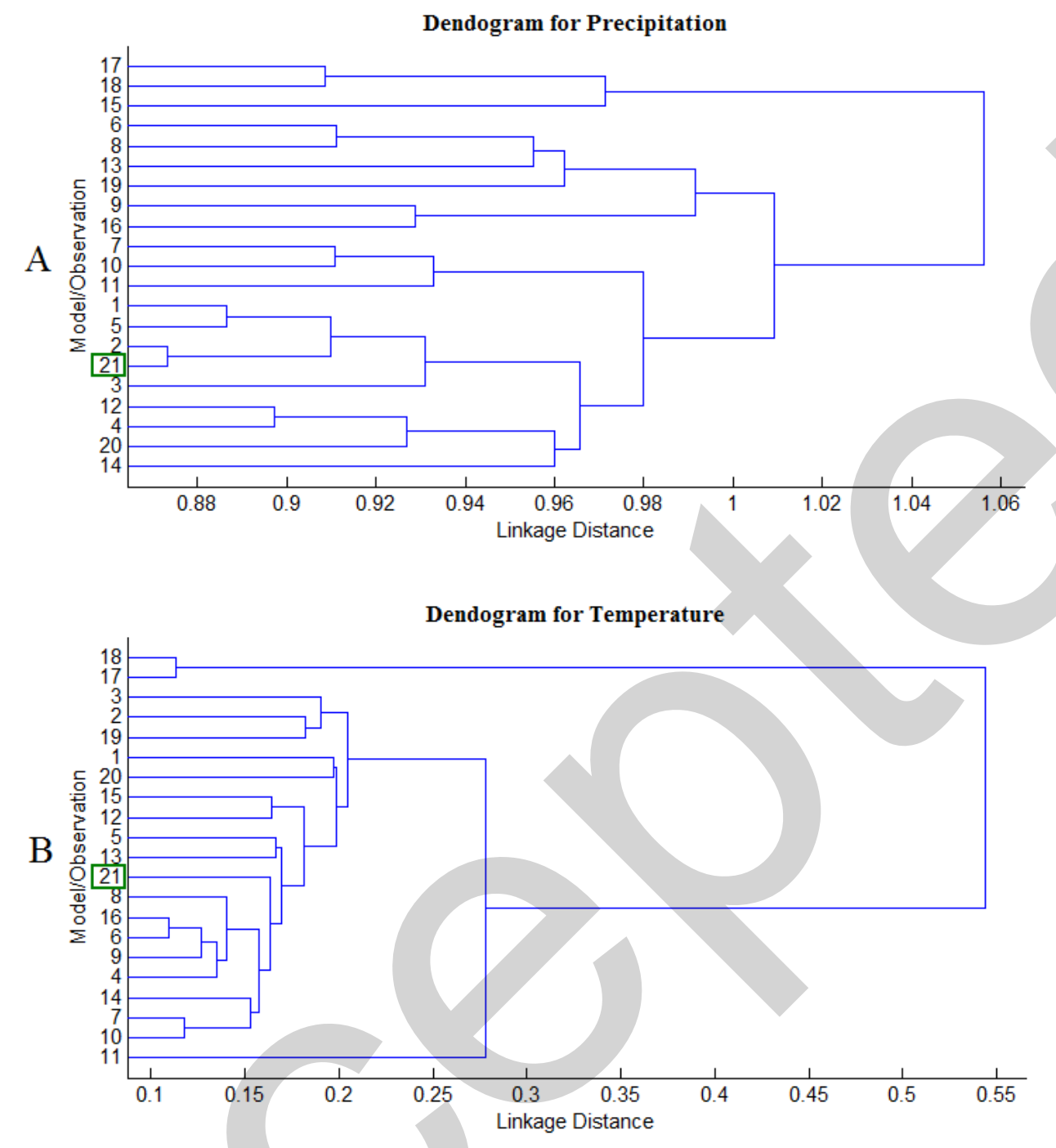

Figure 5. Dendograms generated with cluster analysis. (a) Cluster plot for precipitation dataset and (b) Cluster plots for temperature dataset. Linkage distance (between gridded observational data and GCMs) forms the basis of relative performance of GCM. Successive order of linkage is used to find the proximity of model to gridded observational data. 

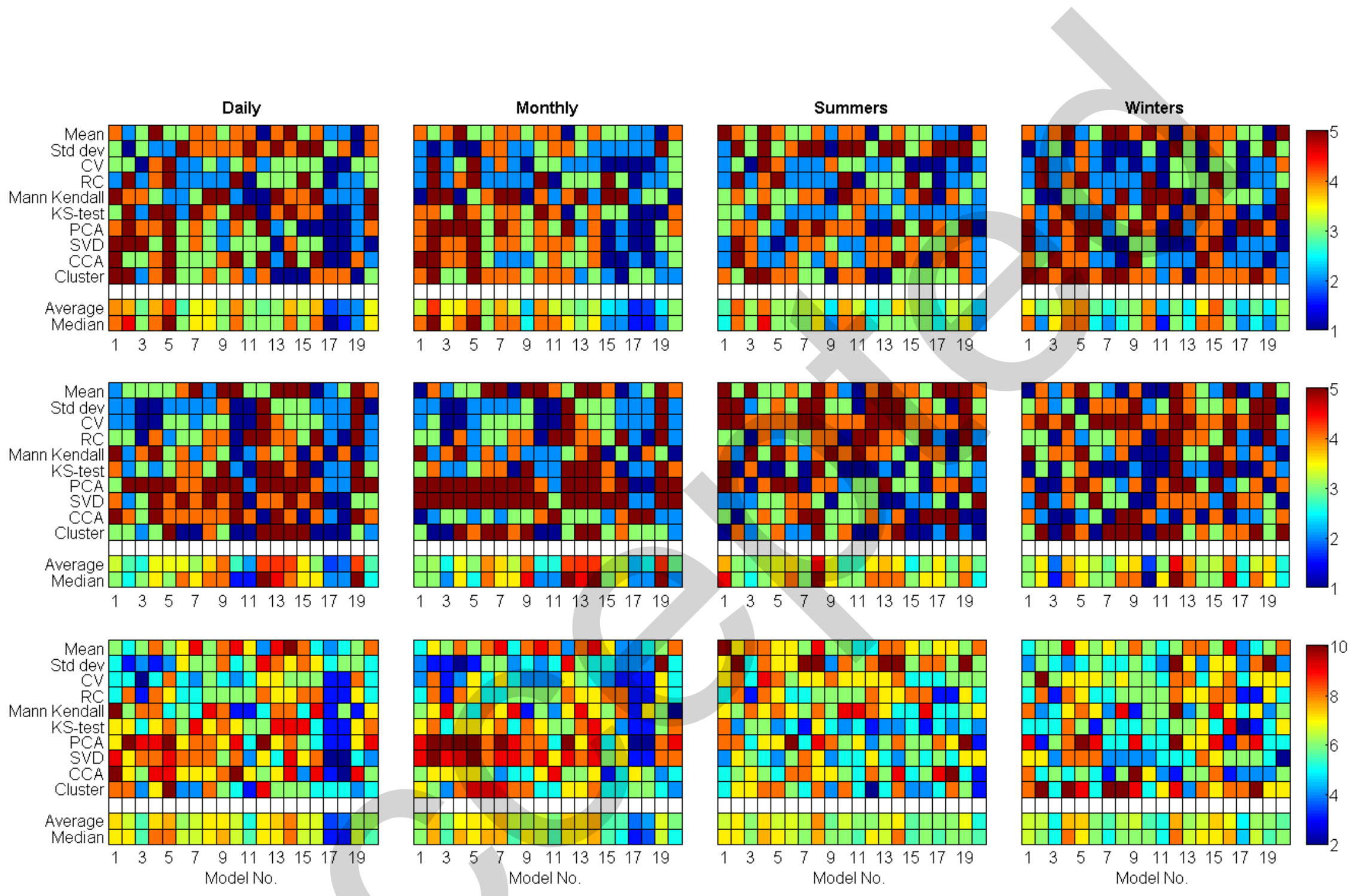

Figure 6. Performance of GCMs as evaluated against gridded observational dataset (Livneh et al. 2013) in each metric based on daily, monthly, and seasonal (summer and winter) data for precipitation (top), temperature (middle), and overall performance (bottom). In each plot, mean and median of all metrics are provided for each model in the last two rows. 

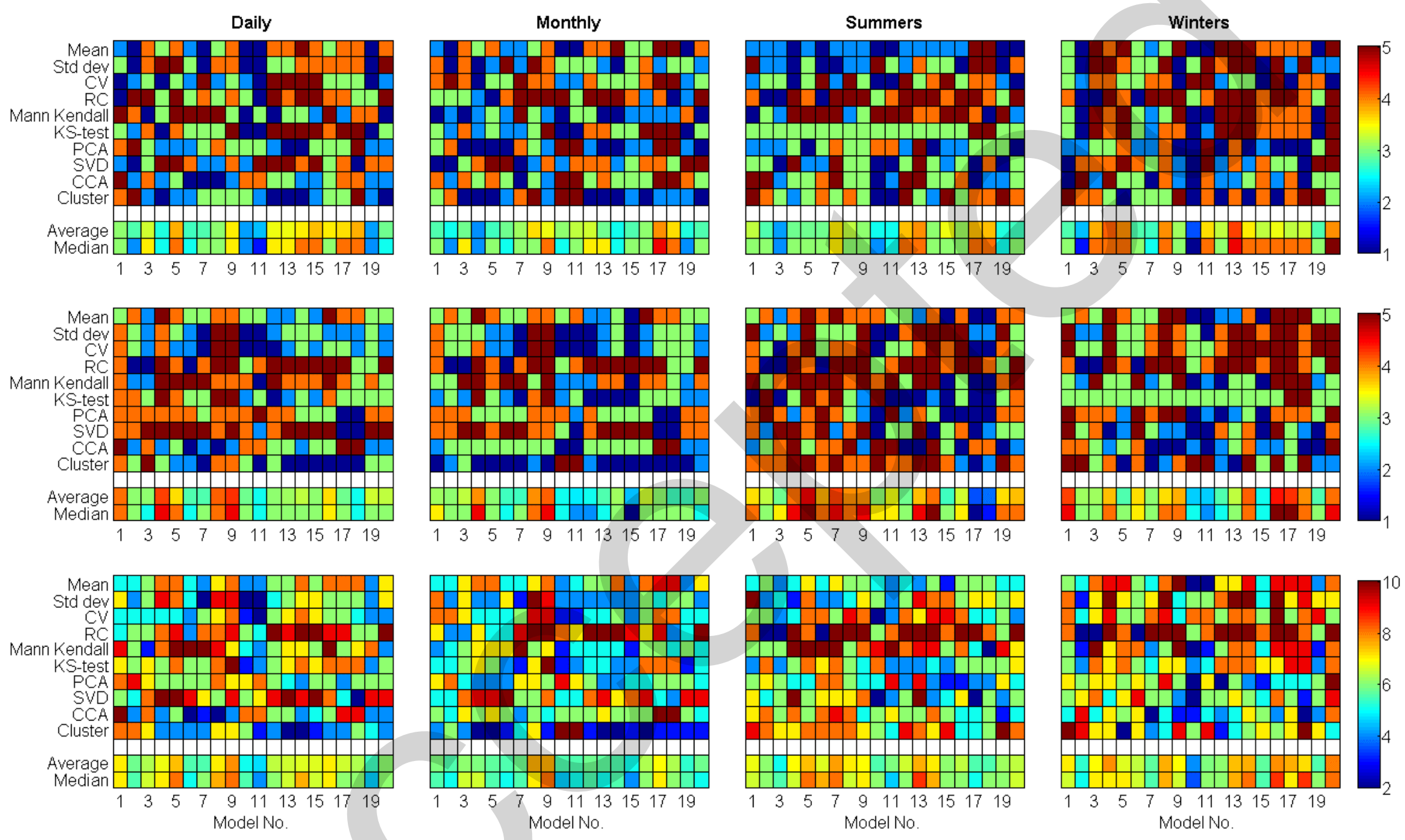

Figure 7. Performance of GCMs as evaluated against changed gridded observational dataset (Abatzoglou 2013) in each metric based on daily, monthly, and seasonal (summer and winter) data for precipitation (top), temperature (middle), and overall performance (bottom). In each plot, mean and median of all metrics are provided for each model in the last two rows. 